\title{
45. RESISTIVITY/POROSITY/VELOCITY RELATIONSHIPS FROM DOWNHOLE LOGS: AN AID FOR EVALUATING PORE MORPHOLOGY ${ }^{1}$
}

\author{
Peter D. Jackson, ${ }^{2}$ Richard D. Jarrard, ${ }^{3}$ Christopher J. Pigram, ${ }^{4}$ and Jonathan M. Pearce ${ }^{2}$
}

\begin{abstract}
Relationships between downhole resistivity/velocity logs and porosity styles, controlled by cementation/dissolution/recrystallization, are investigated using core and downhole logging data from the carbonate-rich sediments encountered during Leg 133 of the Ocean Drilling Program (ODP), northeastern Australia off the Great Barrier Reef. It is shown that although resistivity and velocity are controlled by porosity, the "connectiveness" of the solid phase (velocity) and fluid phase (resistivity) may be more important controls than porosity in these environments.

Velocity logs in this environment are shown to be controlled primarily by the bulk properties of the solid fraction and fluid phases, with interparticle cementation causing significant increases in velocity during lithification. Downhole electrical resistivity $\operatorname{logs}$, in contrast to velocity logs, are shown to respond to the fluid phase in these marine carbonate sediments, where the terrigenous clay fraction is small. Resistivity is shown to be dependent on the connectivity of the pore space in addition to its bulk porosity. The Archie $m$ exponent (derived from resistivity and porosity) is shown (1) to increase to values above 3 when poorly connected vuggy or moldic styles dominate porosity and (2) to be independent of the strength of interparticle cements.

Velocity and resistivity log responses are compared in different diagenetic carbonate environments. The effects of diagenetic processes in shallow-water reefal carbonates are contrasted with the effects of the normal compaction/lithification depth profile in carbonate-rich hemipelagic sediments. Signatures are identified in velocity/resistivity responses that are diagnostic of different diagenetically controlled porosity styles. For example, log responses from well-connected porosity developed in a dolomite, are distinguished from that in sediments having similar porosity, but extensive recrystallization, which may block the pore throats. A dimensionless velocity/resistivity ratio (VR) is proposed to quantify and to enhance the identification of cementation/dissolution/connectivity styles. A theoretical model is proposed that will predict the velocity vs. resistivity (and hence VR) relationships attributed to these different porosity styles. Within a lithified rock, a high VR ratio is shown to represent well-connected porosity, whereas a low VR ratio is shown to represent poorly connected porosity where the pore throats are blocked. This VR ratio is used to identify two substantially different trends within two Miocene reef units identified at Site 816 (Davies, McKenzie, PalmerJulson, et al., 1991). Davies, McKenzie, Palmer-Julson, et al. (1991) and Pigram et al. (this volume) showed that there is evidence of subaerial exposure and fresh water diagenesis within both these reef units. We observed a trend of increasing fabric destruction with depth within the deeper Miocene reef unit at Site 816. Although dolomitization is complete within this unit, matrix recrystalization is seen to increase with depth. We postulate that recrystallization (where the matrix is now composed of dolomite rhombs having an open intercrystalline porosity) has lead to the generation of connected porosity at Site 816 that is seen as high values of the VR ratio. Thin layers having very high VR ratios were identified in the lower unit. One such layer was studied in more detail using formation microscanner (FMS) images. This 0.6-m-thick layer of distinctly lower resistivity has an internal structure that suggests that this may be a solution feature and might constitute a significant pathway for fluid flow in the formation.
\end{abstract}

\section{INTRODUCTION}

The pore morphology within carbonates from the platforms drilled during Leg 133 at Sites 812, 817, 816, and 826 (Davies, McKenzie, Palmer-Julson, et al., 1991) was seen to be extremely variable. This is typical for this type of environment, where diagenesis of reef deposits originally having intricate bioclast-controlled morphology, have been modified by a complex cementation/dissolution history and dolomitization.

Contrasting sedimentological controls act on the propagation of electric currents and compressional sound waves in carbonate-rich sediments, particularly when diagenesis is significant (Focke and Munn, 1987; Fulthorpe et al., 1989). Electrical resistivity depends on the resistance to the flow of electric currents in the pore fluid. On the other hand, sound velocity is controlled by the bulk properties of the solid fraction in a cemented formation (Nobes, 1989). Therefore, although both electrical resistivity and sound velocity exhibit general trends of increasing values with increasing depth of burial, which is

\footnotetext{
'McKenzie, J.A., Davies, P.J., Palmer-Julson, A., et al., 1993. Proc. ODP. Sci. Results, 133: College Station, TX (Ocean Drilling Program).

${ }^{2}$ British Geological Survey, Keyworth, Nottingham NG12 5GG, United Kingdom.

${ }^{3}$ Department of Geology and Geophysics, University of Utah, Salt Lake City, UT 84112 , U.S.A.

${ }^{4}$ Australian Geological Survey Organisation (formerly Bureau of Mineral Resources). P.O. Box 378, Canberra, ACT 2601, Australia.
}

accompanied by a decrease in porosity, they are likely to exhibit different responses to carbonate diagenesis. Therefore, a combined investigation of velocity and resistivity may prove to be a more effective way of assessing pore morphologies in reefal carbonates than by considering resistivity and velocity logs in isolation.

\section{THEORETICAL BACKGROUND}

\section{Relationships of Electrical Resistivity to Porosity}

The electrical resistivity of saturated porous media is described in terms of formation factor (FF) to remove the dependency on the resistivity of the pore fluid, where

FF $=$ Resistivity of Formation/Resistivity of Pore Fluid.

FF has been shown to be related to porosity $(n)$, for any one formation, by various empirical equations that contain generalized constants, such as

$$
\begin{gathered}
\mathrm{FF}=1 / n^{m} \text { Archie (1942), } \\
\mathrm{FF}=a / n^{m} \text { Winsauer et al. (1952). }
\end{gathered}
$$

Archie's equation is probably the most widely used and has been shown to apply to uncemented sediments (Jackson et al., 1978), in 


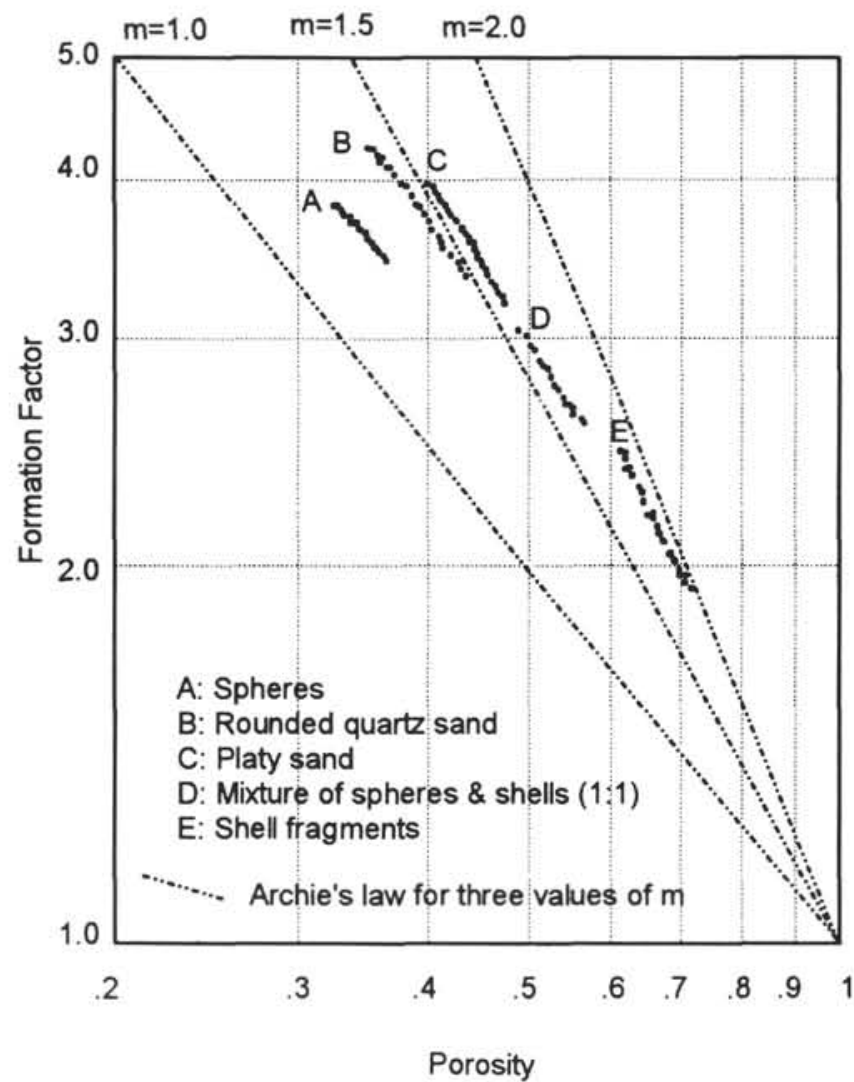

Figure 1. FF vs. porosity, showing the effect of particle shape on the Archie $m$ exponent (Jackson et al., 1978).

which the Archie $m$ exponent is controlled by the shape of the grains. Figure 1 shows the results of compacting a suite of unconsolidated natural and artificial samples with different grain shapes. While each of the samples can be described by the Archie's equation with different values of $m$, which are meaningful in terms of particle shape (and, hence, style of pore morphology), the combined plot of data from samples $\mathrm{C}, \mathrm{D}$, and $\mathrm{E}$ have an intercept at $n=1$ that is not equal to 1 ; instead it could be described by Winsauer's equation $\left(\mathrm{FF}=a / n^{m}\right)$. For shallow-water carbonates, Focke and Munn (1987) showed that the Archie $m$ exponent is constant and approximately 2 when interparticle porosity dominates (Fig. 2A) and is more variable and substantially higher when porosity is moldic or vuggy, being linearly related to porosity as shown in Figure 2B.

Moldic and vuggy porosity styles define a morphology where a substantial proportion of the porosity is unconnected or semi-isolated and, therefore, makes a proportionately smaller contribution to the measured electrical resistivity. In such cases, an increase in poorly or unconnected porosity implies an increase in Archie $m$ because in the relationship,

$$
\mathrm{FF}=1 / n^{m}(\text { Archie, 1942), }
$$

if the porosity $(n)$ increases without a corresponding decrease in FF, then the exponent $(m)$ must also increase. This is significant because the different relationships between porosity $(n)$ and exponent $(m)$ for interparticle and vuggy porosity styles, described above, suggest the exponent $(m)$ can be used as an independent indicator of diagenetic processes (e.g., dolomitization).

At very low porosities, under large lithostatic stress, Hilchie (1989) described increases in Archie $m$ that were far greater for moldic porosities than for interparticle ones and indicated that Archie $m$ is related to porosity in vuggy sediments, as follows:

$$
m=1.87+0.019 / n \text {. }
$$

This relationship is valid for very low porosity carbonates, and shows that Archie $m$ increases as porosity decreases, with the latter relationship known as the "Shell" equation (Hilchie, 1989).

These relationships illustrate the lack of a fundamental general relationship relating FF and porosity, but that a parameter, Archie $m$, derived from Archie's equation ( $\left.\mathrm{FF}=1 / n^{m}\right)$ may be useful for describing the style of porosity. Traditionally, Archie's $m$ exponent has been linked with greater cementation in rocks having interparticle porosity and is often referred to as the "cementation exponent" (Winsauer et al., 1952). For shallow-water carbonates, values of Archie $m$ near 2 are indicative of well-connected interparticle porosity, while values in the range of 2.5 to 5 are typical of vuggy or moldic porosity (Focke and Munn, 1987).

\section{Relationship of Velocity to Porosity}

For low-porosity cemented sediments of a variety of mineralogies, the porosity/compressional wave velocity relationship of Wyllie et al. (1956) has proved appropriate for almost half a century. Wyllie et al.'s (1956) "time-average" relationship is as follows:

$$
n=\left(D t_{\text {rock }}-D t_{m a} /\left(D t_{f}-D t_{m a}\right),\right.
$$

where $D t_{\text {rock }}$ is the traveltime (in microseconds/foot) in a porous rock; $D t_{m a}$ is the matrix (zero fractional porosity) traveltime; $D t_{f}$ is the traveltime of the pore fluid, and $n$ is the fractional porosity. Velocity $\left(V_{p}\right.$, in kilometer/second) is related to traveltime $(D t)$ by

$$
V_{p}=304 \cdot 8 / D t \text {. }
$$

Wyllie et al.'s time-average equation, although empirical, is based on theoretical concepts: it assumes that the traveltime of sound in a porous rock is equal to the time spent moving through a corresponding volume of fluid, plus the time spent moving through a corresponding volume of zero-porosity rock. Unfortunately, Wyllie et al.'s equation is reasonably accurate only for the generally low porosities of interest in the oil industry. For all porosities of greater than about $25 \%$, this equation greatly overestimates velocities.

For unconsolidated and uncemented sediments, Wood (1941) simplified the theoretical Hookean elastic equations (e.g., Gassmann, 1951) by assuming that the rock solids and fluid lacked rigidity and, thus, both rigidity modulus and skeletal bulk modulus equal zero. His resulting relationship between velocity and porosity predicts much lower velocities than does Wyllie et al.'s equation at a given porosity. At best, this relationship can be expected to be appropriate only for porosities above 0.6 (Laughton, 1957).

Raymer et al. (1980) attempted to fill the gap between the lowporosity usefulness of Wyllie et al.'s (1956) relationship and the possible very high-porosity usefulness of Wood's relationship (1941). Unfortunately, Raymer et al. (1980) had only sparse data for porosities above $35 \%$. In our tests of the Raymer relationship using high-porosity data from ODP and DSDP, we found it to be a poor predictor (Jarrard et al., 1989; Fulthorpe et al., 1989). In contrast, Nobes (1989) found that a simple average of the Wyllie et al. and Wood relationships was successful in predicting velocity behavior in pelagic sediments (e.g., Nobes et al., 1991):

$$
D t=(n) D t_{\text {Wood }}+(1-n) D t_{\text {Wyllie. }}
$$

For pelagic or reefal carbonates such as these, we concur with Urmos et al. (in press) and conclude that no single, comprehensive relationship is seen between porosity and velocity. Urmos et al. (in 
A

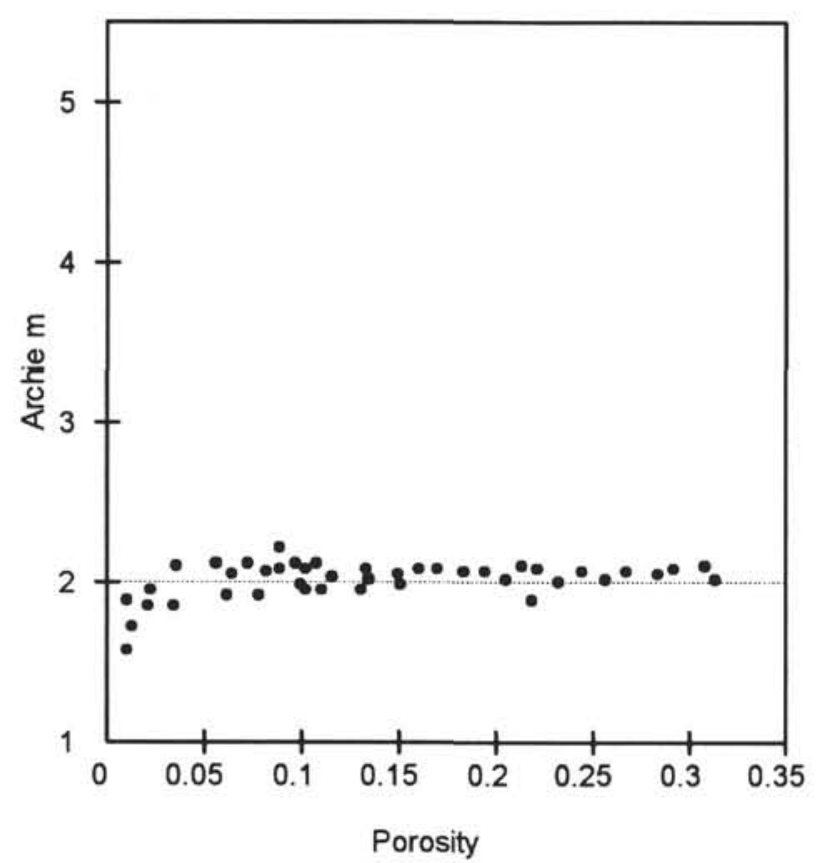

B

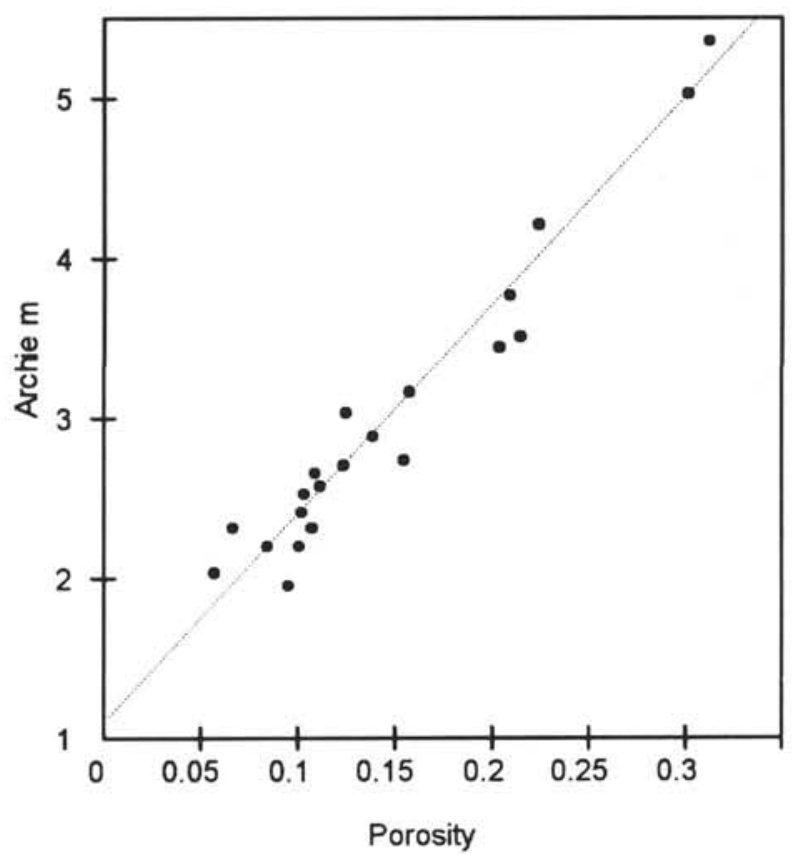

Figure 2. Archie $m$ values vs. porosity for interparticle (A) and moldic (B) porosity styles (after Focke and Munn, 1987).

press) found substantial differences in porosity/velocity relations between Sites 803 and 807 on the Ontong-Java Plateau. However, nearby Site 586, in sediments similar to Site 807 , did have a relationship similar to that at Site 807 (Fulthorpe et al., 1989).

Of the published porosity/velocity relationships, that of Nobes (1989) is the most applicable to Leg 133 as it considers the transition that occurs during lithification/cementation. Initially, during compaction, when the fluid phase elastic constants dominate, Wood's relationship will be more applicable, while after cementation has commenced and the elastic constants of the solid phase are dominant, Wyllie et al.'s relationship will be the most relevant.

An empirical velocity/porosity relationship has been developed by Urmos et al. (in press) for a reefal-carbonate environment similar to that encountered during Leg 133. Their relationship has been converted to the generalized form:

$$
V_{p}=1 /(A[n]+B)
$$

where $A$ and $B$ are constants, equaling 1.0672 and -0.1156 respectively (Urmos et al., in press). Wyllie et al.'s equation can also be used in this form. We calculated values of 0.517 and 0.149 for constants $A$ and $B$, respectively, using a velocity of $1.5 \mathrm{~km} / \mathrm{s}$ for the fluid phase and a velocity of $6.7 \mathrm{~km} / \mathrm{s}$ for the solid phase (dolomite, after Hilchie, 1989).

\section{PORE MORPHOLOGY/FF/VELOCITY/ ARCHIE $m$ /POROSITY}

During Leg 133, core recovery from cemented deposits (reef, skeletal) was generally poor (Davies, McKenzie, Palmer-Julson, et al., 1991), with large intervals having no recovery (e.g., Site 817 depth interval of 570 to $600 \mathrm{mbsf}$ ). In other intervals, complex log responses corresponded to a small number of samples, which cannot be taken to be representative (e.g., Site 817 depth interval of 605 to $615 \mathrm{mbsf}$ ). Thus, logging data provide the only continuous information over many sections of the boreholes drilled in carbonate platforms during Leg 133.
Some indication of pore morphology can be obtained directly from traditional parameters developed for oil reservoirs, such as the exponent $m$ in Archie's equation (Archie, 1942), as already described. This exponent can be calculated from resistivity and density logs using assumptions for grain density (needed to estimate porosity) and pore-fluid resistivity. The following uses temperature-corrected seawater resistivities to calculate pore-fluid resistivity and carbonate density to calculate porosity. Although errors may be introduced by these assumptions, they are secondary compared to porosity, cementation, and pore morphology variations observed both in situ and in the recovered core.

Previous work outlined above showed the Archie $m$ exponent to be controlled by the shape of the particles in unconsolidated sediments (Jackson et al., 1978) and the proportion of the porosity that is moldic or vuggy (thus, poorly connected) in carbonate reservoirs (Focke and Munn, 1989). Thus, in lithified carbonate sediments where moldic and vuggy porosities are common, high values of Archie $m$ are expected (in the range 2 to 5 ).

When considering intergranular pore morphologies (e.g., sandstones and unconsolidated sediments), a concept of increased path length or "tortuosity" has been widely adopted in the literature (e.g., Schopper, 1966) to describe the control of pore morphology on the Archie $m$ exponent. The concept of "tortuosity" is limited when considering the pore morphology of real marine sediments, because it seeks to characterize complex three-dimensional phenomena using a one-dimensional parameter. Furthermore, when considering intergranular flow, the "tortuosity" of the pore space has tended to be the focus, rather than our attempting to understand the three-dimensional flow of electric currents in realistic pore morphologies.

In carbonate reservoirs, the concept of vugs and molds, where the connections between them control the measured resistivity, has obvious merit. This concept explains the reduced increase in resistivity with overburden pressure seen in carbonates having well-connected interparticle porosity, compared with those having moldic porosity (Focke and Munn, 1987; Hilchie, 1989); any reduction in size of the 
connections between molds might result in a significant increase in resistivity, while porosity might remain almost unchanged.

To study three-dimensional electrical current flow in porous media, a three-dimensional numerical electrical resistivity modeling technique (Reece, 1986; Jackson et al., 1990; Jackson et al., 1991) was adapted to simulate a simplified, generalized porous medium. The strategy adopted was to study the three-dimensional electrical flow in a single pore and to study its connections to other pores in a larger conceptual pore space. The authors sought to investigate three-dimensional interactions of electric currents with pore channels (i.e., connections) and pores. Our numerical models were simplified to include orthogonal uniform pore channels and cubic pores. These geometrical shapes do not seek to characterize a porous medium, but rather to describe changes from pore channels to pores, and to simulate realistically channels that do not have significant flows of electric current in them, although they have a low-resistance connection to the pore space.

Two morphological features of porous media were considered, namely pores and their connecting channels. The numerical simulation includes the ability to study the effect of relative changes in pore size and channel width on Archie's $m$ relationship for the numerical model of the pore space. The numerical model of the porous medium simulates a fluid-filled pore space held in a unit cube of "insulator," as shown in Figure 3. The porosity, fluid resistance, and formation resistance of the numerical model of porous media were calculated using the three-dimensional numerical simulation described above. In turn, this allowed us to calculate the FF and Archie's $m$.

For example, if no pore appeared in Figure 3, only the pore channel parallel to the direction of the electric field would carry electrical current. Thus, not all the "simulated" fluid would take part in the electrical conduction. This extremely simple example demonstrates that an Archie $m$ value above 1.0 is possible when no tortuous flow of electric current occurs; this is generally applicable to sediments
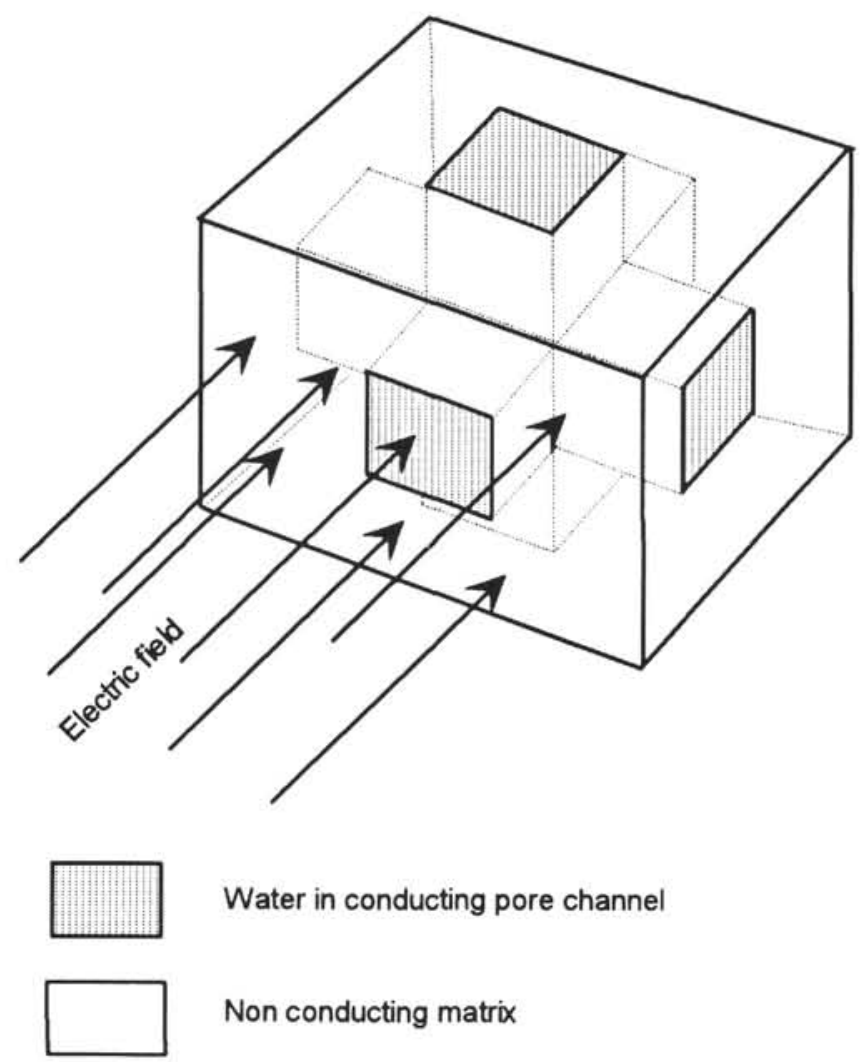

Water in conducting pore channel

Non conducting matrix

Figure 3. A model for simulating three-dimensional flow of electric current in orthogonal pore channels. having a high degree of interconnected interparticle or fracture porosity (e.g., Brace et al., 1965). For a single, straight pore channel, aligned parallel to the electric field, the value of Archie's $m$ should be 1.0 , as shown below.

For a unit cube and a fluid resistivity of $1.0 \mathrm{ohm}-\mathrm{m}$, and a fractional porosity $(n)$,

$$
\begin{aligned}
\text { Fluid resistance }= & 1.0 \text { ohms }(\text { from the definition of } \\
& \text { resistivity }),
\end{aligned}
$$

Formation resistance $=1 / n$ ohms $($ cross-sectional area of channel $=n$ ),

Formation factor $(\mathrm{FF})=1 / n$,

$$
\left.m=1 \text { (Archie's equation, } \mathrm{FF}=1 / n^{m}\right) .
$$

The effect of changing the diameter of the connecting channels, assuming no pores, can be seen in Figure $4 \mathrm{~A}$, where the highest porosity indicates the largest connecting channels. This result indicates that porosity may weakly control the Archie $m$ exponent when the pores and connecting channels offer similar resistance to the flow of electric current.

A

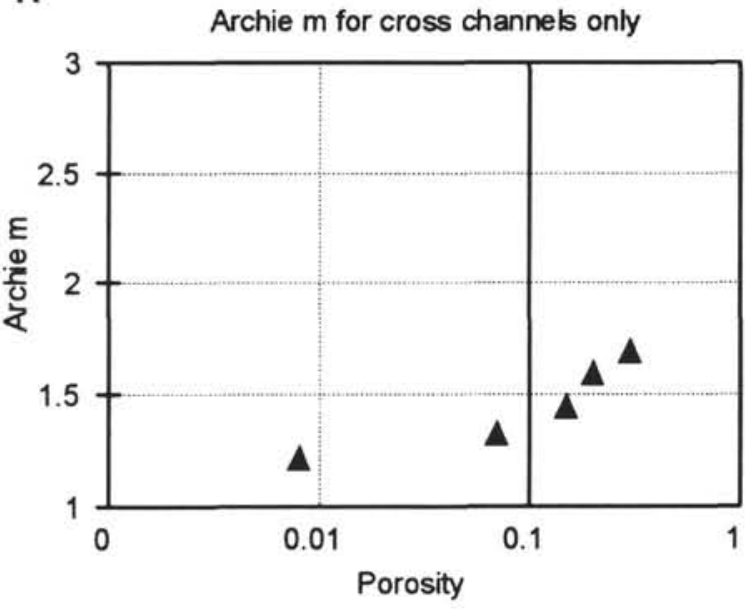

B

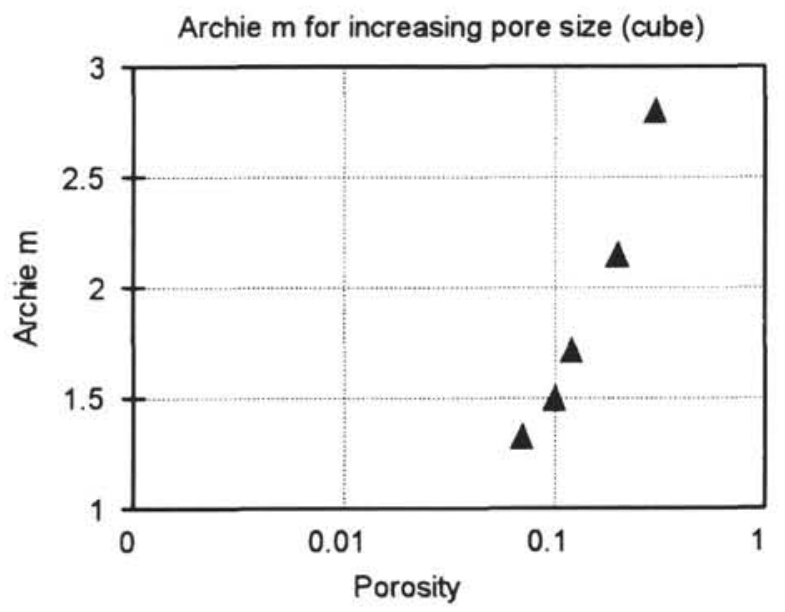

Figure 4. Plot of porosity vs. Archie $m$ for connecting channels of increasing diameter (A) and fixed size connecting channels and increasing size of cubic pore (B). 
Figure $4 \mathrm{~B}$ shows the results when the central pore was gradually increased in size, while the connecting channels were maintained at a fixed size. In this situation, Archie $m$ is directly related to the fraction of pore space that is pore (excluding connecting channels). Values are as high as those attributed to samples with moldic porosity (Focke and Munn, 1987).

The following conclusions were drawn from the numerical modeling:

1. An Archie $m$ exponent greater than 1.0 does not necessarily indicate tortuous flow or increased path length.

2. Not all connected porosity takes part equally in the flow of electric current.

3. In moldic pore morphologies, Archie's $m$ is high, with porosity controlled by the molds and vugs, and resistivity (FF), by the resistance of the connecting channels.

4. The Archie $m$ exponent need not be related to degree of cementation.

5. A single, straight pore channel aligned parallel to the flow of electric current will have an Archie $m$ of 1.0.

In carbonate sediments, where both dissolution and cementation can exist, a wide range of Archie $m$ values is to be expected (Focke and Munn, 1989). For example, well-connected interparticle porosity may be developed during dolomitization, while at later times, it is possible for recrystallization to block the pore channels; the Archie $m$ exponent would increase rapidly between these two cases.

In conclusion, resistivity, porosity and Archie $m$ are controlled by the distribution and connectivity of the fluid phase within a rock, and are not sensitive to the elastic properties of the solid phase. For example, an unconsolidated sediment and a sucrosic dolomite with a high degree of interconnected interparticle porosity may have similar porosities and values of Archie $m$.

\section{INTEGRATING RESISTIVITY AND VELOCITY}

Velocity and resistivity logs are often termed "porosity" logs, because porosity is often the primary control on resistivity and velocity during normal compaction/lithification observed in marine sediments (Jarrard et al., 1989, Urmos et al., in press). Velocity and resistivity logs from Hole $817 \mathrm{D}$ are representative of a number of lithologies and exhibit a general consolidation trend as a primary feature, with marked secondary features that record changes in lithology/lithification/diagenesis (Fig. 5).

The velocity and FF (corrected for temperature) logs for Hole $817 \mathrm{D}$ in Figure 5 illustrate these primary and secondary trends.

Crossplots of FF and velocity vs. porosity, using independent downhole log data (i.e., derived from resistivity, velocity and density logs, respectively), for Site 817 can be seen in Figure 6 to show the general increase in velocity and resistivity with decreasing porosity, overprinted by a high degree of scatter. The amount of scatter in the data might be controlled by changes in cementation and style of porosity, both of which are extremely variable, based on the samples that were collected (core recovery was poor: $5.2 \%$ in Hole $817 \mathrm{D}$, $300-700 \mathrm{mbsf}$ ). Archie $m$ values at Site 817 are shown as a function of porosity in Figure 6; high values between 2 and 3 are indicative of moldic porosity, which is in agreement with core data. A trend of increasing Archie $m$ (from 1.5 to 2.0) with increasing porosity can be seen, which is typical of the compaction/lithification profiles seen during Leg 133 (Davies, McKenzie, Palmer-Julson, et al., 1991).

In general, the velocity and resistivity logs of Leg 133 showed a direct correlation. However, exceptions were observed, for example, 150 mbsf at Site 814 (Fig. 7), where an increase in velocity exists without a corresponding increase in resistivity. The core description, at this depth, indicates a dolomitized bioclastic packstone with moldic porosity that has been subjected to subaerial exposure (Davies, McKenzie, Palmer-Julson, et al., 1991).
Both velocity and resistivity logs in Figure 7 display sharp maxima over a thin layer at 135 mbsf. This thin layer has low porosity and high density, suggesting that an increase in cementation has taken place, as is common in this type of depositional environment. Core recovery was poor at this depth, and no core samples could be unequivocally attributed to this thin layer (134-136 mbsf Hole 814A). However, samples were recovered that came from between 135 and 155 mbsf in Hole 814A (Cores 133-814A-17H and - 18X), which have been described by Davies, McKenzie, Palmer-Julson, et al., (1991) as highly porous, lithified, dolomitized bioclastic packstones.

Section 133-814A-18X-1 is of particular interest because it passed through the depth interval from 148 to 151 mbsf in Hole 814A, where an increase in velocity can be seen in Figure 7, without a corresponding increase in resistivity (FF). The porosity log shows a small decrease within this depth interval. The increase in velocity accompanied by a decrease in resistivity might be the results of increased cementation and the development of connected porosity. Fragments of Sample 133-814A-18X-1, 4-10 cm (Fig. 8) were investigated by using the scanning electron microscope (SEM) to assess the style of porosity and cementation. Results (Fig. 8) show large-scale moldic porosity up to $500 \mathrm{~mm}$ in diameter, which may result from the dissolution of shell material. Some infilling of sheltered porosity by euhedral calcite can be seen. The fringing growth of subhedral calcite (seen in Fig. 8) lines pore walls, but does not appear to block pore throats. Furthermore, fine-grained "matrix calcite," which is seen to fill in voids, is itself microporous and of an open structure. This sample exhibits extensive cementation from calcite, while still maintaining a substantial connected porosity, where the infilling cementation shows no evidence of blocking pore throats. The value of Archie's $m$ decreased from 1.80 to 1.53 within the depth interval 148 to 151 mbsf. Thus, one has an example of a cemented rock that has a well-connected pore space. The divergent trends of the resistivity and velocity logs at 148 to $151 \mathrm{mbsf}$ in Hole 814A (Fig. 7) can be explained by the cementation and the connected porosity described above, although uncertainty exists about the exact depth of the sample because of the poor core recovery.

The opposite was observed during downhole logging at Site 824 at a depth of 136 mbsf. The sediments at Site 824 were described by Davies, McKenzie, Palmer-Julson, et al., (1991) as pure carbonate, periplatform, pelagic, and shallow-water carbonates. The velocity log shows a dramatic decrease in the middle of a layer that is centered at $136 \mathrm{mbsf}$ (as shown in Fig. 9). This layer is characterized by an increase in resistivity of $200 \%$ over the interval from 130 to $140 \mathrm{mbsf}$. The velocity log increases at the upper and lower limits of the layer by from $60 \%$ to $70 \%$, decreasing in the center. The form of the velocity and resistivity logs within the interval might be explained by an increase in porosity, coupled with a decrease in connectivity. In this case, the resistivity log should be insensitive to changes in absolute porosity, while the velocity $\log$ should be insensitive to the connectivity of the pore space and vice versa. A density log was not run at Site 824 ; which is why the Archie $m$ data are not available as supporting evidence (were there a large porosity with poor connectivity the Archie $m$ parameter would be high, $>3$ ). The decrease in velocity is so great that one can doubt its reliability, even though two runs were corrected and merged on board the ship (Davies, McKenzie, Palmer-Julson, et al., 1991); however, the example serves to show the range of control that porosity, cementation and connectivity have on resistivity and velocity logs.

Core samples were available for the depth interval above, and SEM morphology images were used to investigate the cementation and style of porosity, particularly its connectivity. Results (Fig. 10A) show extensive cementation in the hand specimen, which blocks off the visible porosity. This cementation is seen in the SEM image (Fig. $10 \mathrm{~B}$ ) as pervasive crystal growth, which is blocking pore throats, but is accompanied by extensive intercrystal porosity. In this case, the velocity appears to respond to a large unconnected porosity, while the resistivity increases because of poor connectivity. The authors suggest that it is entirely plausible to expect large intercrystal porosities and 


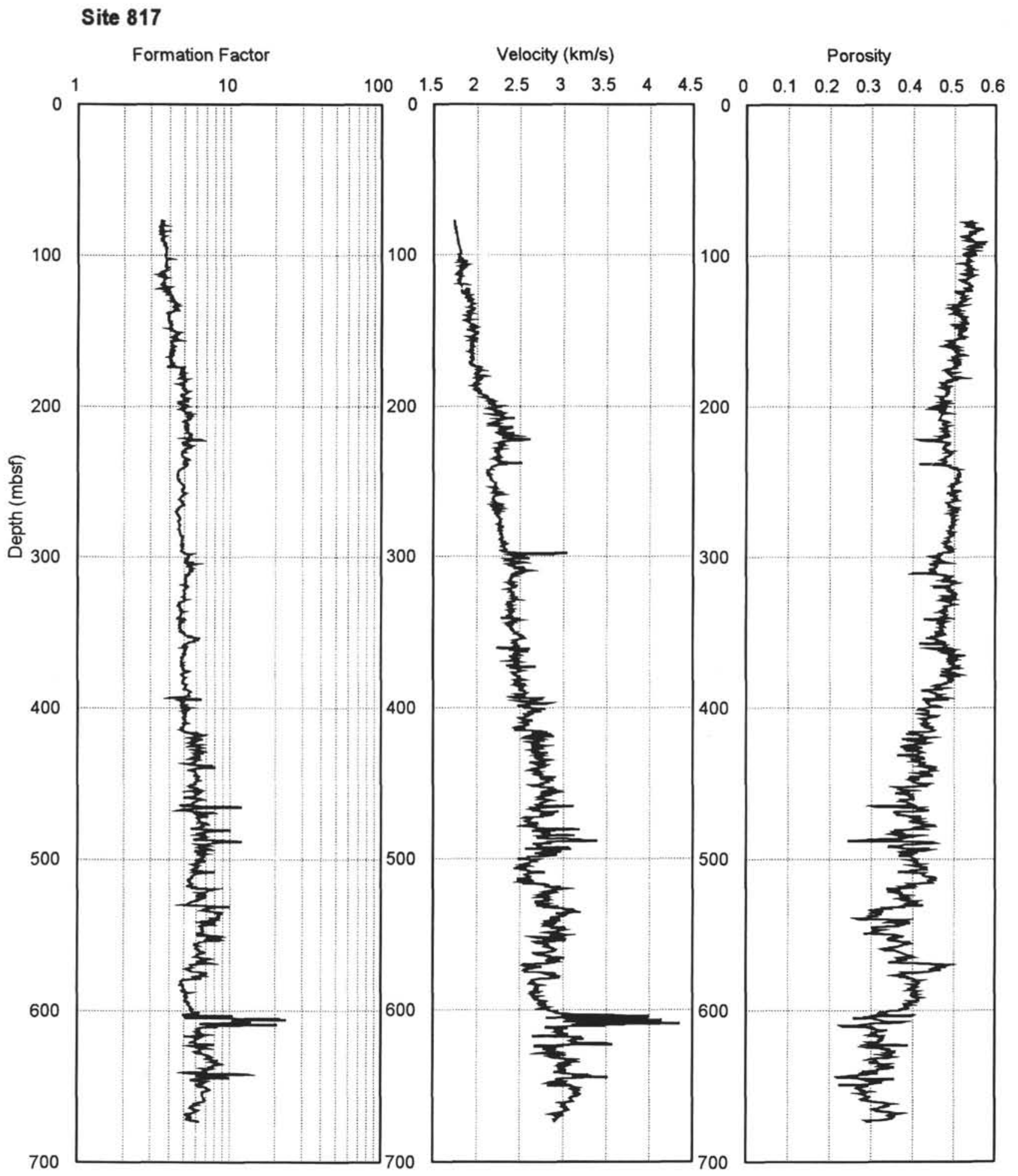

Figure 5. In-situ FF (from resistivity log, corrected for temperature), velocity and porosity (from density) vs. depth at Site 817.

high resistivities where extensive recrystallization has occurred that blocks pore throats; in such cases, dissolution of the 'blocking' crystals may reduce the resistivity dramatically without significantly affecting either porosity or velocity.

An example of moldic porosity in dolomite is shown in Figure 11A (Sample 133-817D-38R-1, 17-20 cm), where original shell material has been completely dissolved, leaving many molds and vugs.
The corresponding SEM photomicrograph (Fig. 11B) shows welldeveloped intercrystalline porosity and indicates that the pore throats were not blocked by finer material. Thus, we have a sample with dual porosity: an intercrystalline microporosity between dolomite rhombs, and a moldic macroporosity from dissolution of bioclasts.

The resistivity and velocity logs that correspond to Sample 133817D-38R-1, 17-20 cm, are shown in Figure 12, for the depth interval 

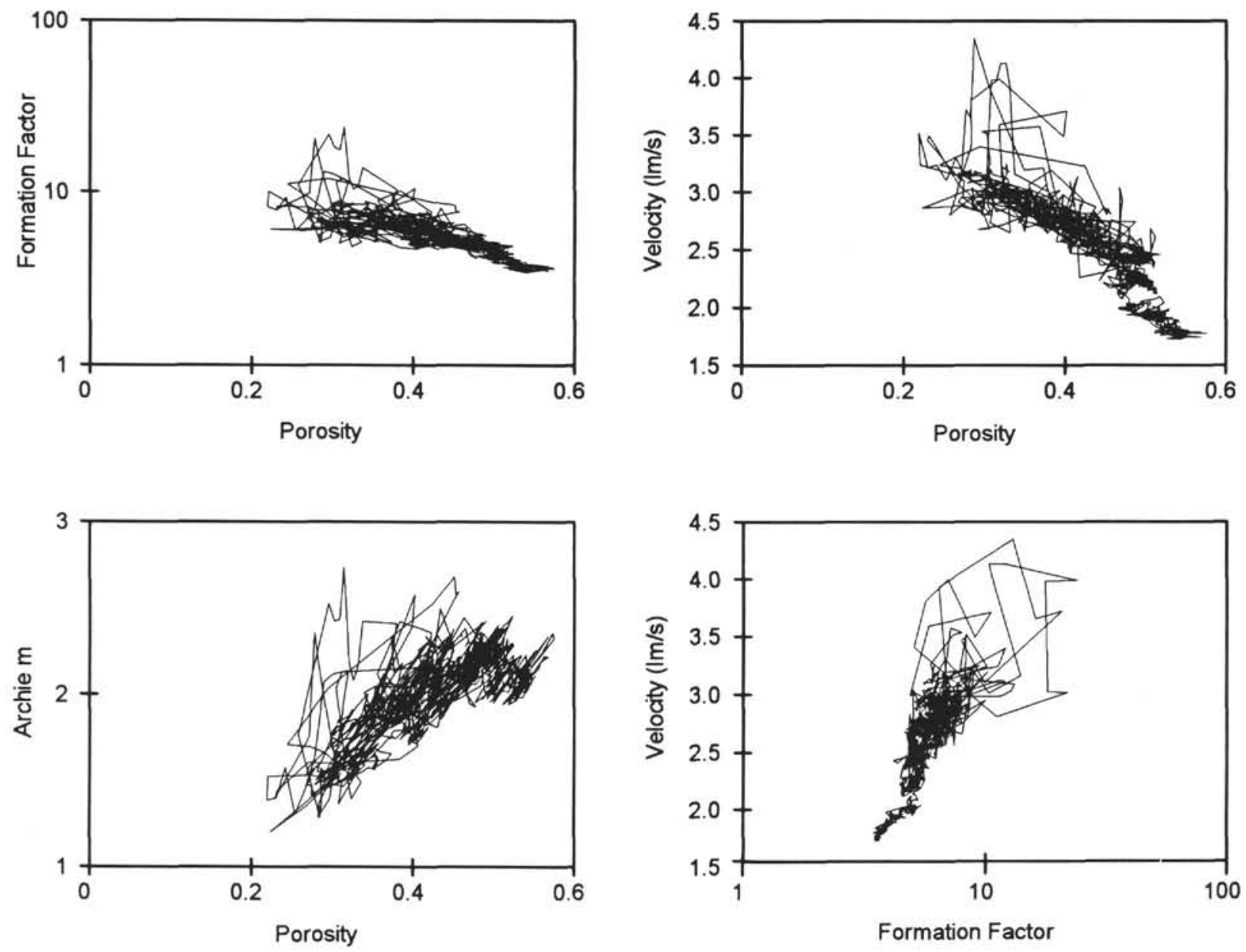

Figure 6. Velocity vs. porosity, FF vs. porosity, Archie $m$ exponent vs. porosity, and velocity vs. FF for Site 817 from downhole logs. Lines connecting data values (from points that are adjacent downhole) are plotted.

from 580 to 630 at Site 817 . Both resistivity and velocity logs increase markedly over this region, which would normally be taken as an indicator of a reduction in porosity. However, the corresponding increase in Archie $m$ value (Fig. 12) to 2.8 suggests that vugs and molds may be present, as these are the most likely features implied by this high value of Archie $m$. Evidence from the density log shows that porosity increased within this interval (600 to 610 mbsf), suggesting that cementation and moldic porosity are the controlling factors on velocity and resistivity, respectively, rather than just porosity.

The above discussion illustrates the differing controls on electrical resistivity and acoustic velocity that are evident in diagenetically altered carbonate sediments. If one could isolate these secondary controls on the velocity/resistivity relationships, then it might be possible to derive a parameter that is more sensitive to the style of porosity, its connectivity, and cementation.

\section{Secondary Controls on Velocity and Resistivity}

General trends may be studied using crossplots in which two measured or computed parameters are plotted on one graph, rather than as functions of depth. Crossplots for Sites 820 and 816 are presented in Figures 13 and 14, where mechanical compaction and carbonate diagenesis, respectively, are the dominant controls on porosity.

Site 820 is located in $278 \mathrm{~m}$ of water, on the upper continental slope east of Cairns (Grafton Passage). At Site 820 (Fig. 13) wackestone/ mixed sediment were recovered, interbedded with coarser bioclastic packstones. These sediments were deposited on the outer edge of an upper-slope terrace in front of the Great Barrier Reef. This site is in a position to receive both shelf-marine and terrigenous sediment fluxes. One objective of the site was to investigate the possible sea-level signal that resulted from changes in the primary source of sediment flux, which was terrigenous at low sea levels and shelf marine at high sea levels (Davies, McKenzie, Palmer-Julson, et al., 1991).

Site 816 is more complicated than Site 820 in that an unconformity occurs at $91 \mathrm{~m}$, separating unconsolidated hemipelagic sediments of Pliocene-Pleistocene age from shallow-water middle Miocene proximal lagoon carbonates in which substantial dolomitization has occurred. Site 816 is situated on the northwestern corner of the Marion Plateau in a water depth of $440 \mathrm{~m}$. The Miocene reef was divided into two lithostratigraphic units at a depth of $163.7 \mathrm{mbsf}$ (Units II and III, Davies, McKenzie, Palmer-Julson, et al., 1991). Both show indications of subaerial exposure and freshwater diagenesis (Davies, McKenzie, Palmer-Julson, et al., 1991).

Results of crossplots for Site 820 (Fig. 13) show simple, linear relationships that indicate the primary control of porosity on both resistivity (FF) and velocity. There is not a strong control of porosity on the Archie $m$ exponent (because Archie $m$ is limited to a range of 1.75 to 2.0 ). This range is consistent with relatively well-connected porosity and a minimal number of vugs.

The crossplot of velocity vs. FF (Fig. 13) shows a linear relationship with modest scatter. This scatter is expected, as a result of the rhythmic variations between terrigenous and shelf-marine sources. The appropriate straight-line relationship suggests unconsolidated, 


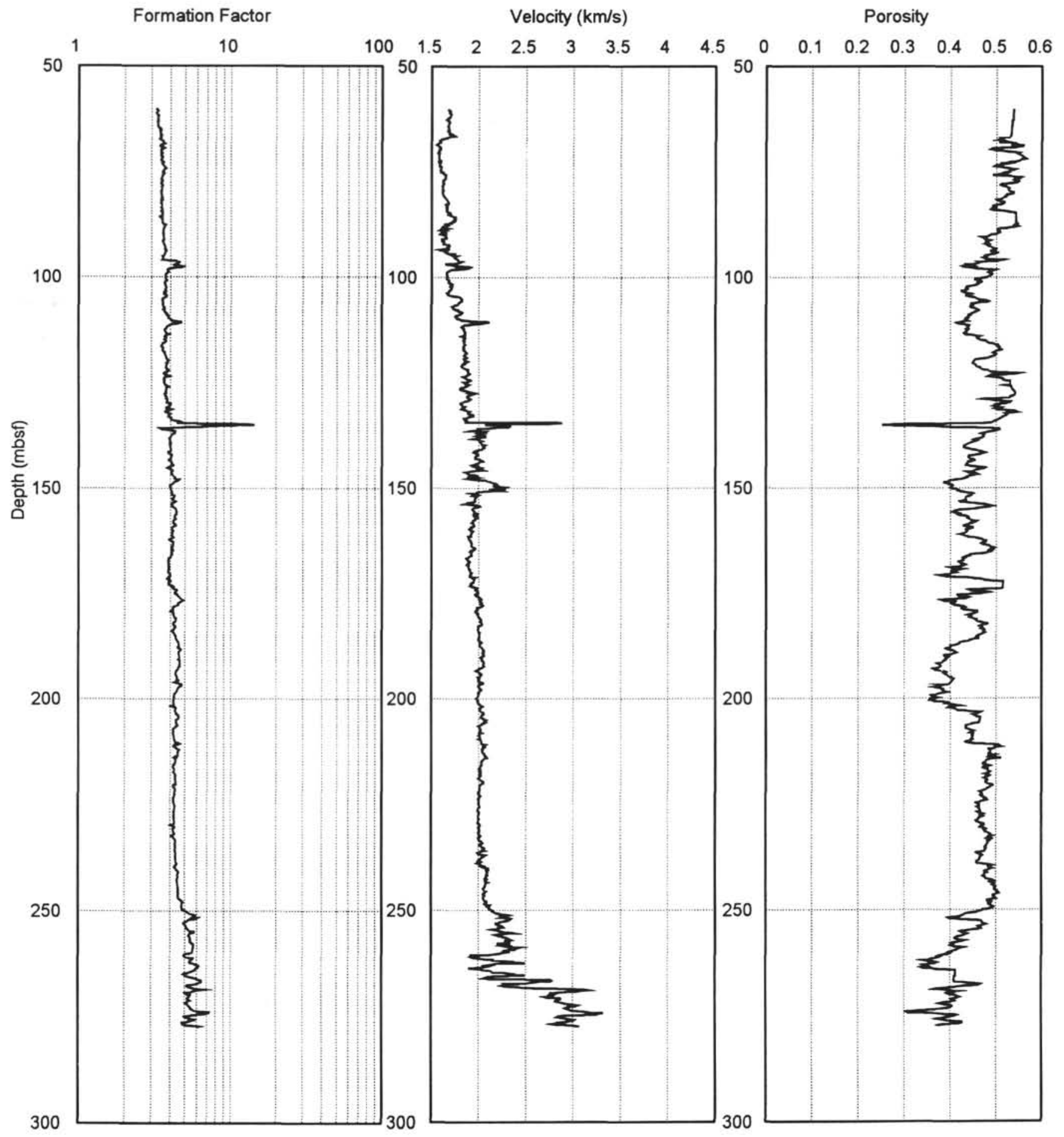

Figure 7. Downhole resistivity, velocity, and porosity (from density) logs for Site 814 showing an anomalous response at $150 \mathrm{mbsf}$.

unlithified sediments nearest the seafloor (velocity $=1.6 \mathrm{~km} / \mathrm{s} ; \mathrm{FF}=$ 4.0 ), moving down to more compacted and lithified sediments of lower porosity (velocity $=2.5 \mathrm{~km} / \mathrm{s} ; \mathrm{FF}=10$ ) in the deepest portions of Hole 820B.

Crossplots for Site 816, on the other hand (shown in Fig. 14), indicate the complexity introduced in a diagenetically controlled shallow water carbonate environment. The velocity/porosity relationship at Site 816 is described by three rather than a single relationship. In addition to the relationship observed at Site 820, two segments with significantly different slopes are seen at Site 816 (Fig. 14). The hemipelagic Pliocene-Pleistocene sediments above $91 \mathrm{mbsf}$ have the lowest velocity, as these are below $1.8 \mathrm{~km} / \mathrm{s}$ and up to $50 \%$ porosity (as shown in the logs in Fig. 15). The FF/porosity cross plot is linear (Fig. 14), with substantial scatter, indicating the likelihood of a wide variability in Archie $m$, which is confirmed by the results shown in Figure 15. The wide variability of Archie $m$ at Site 816, compared to Site 820 , is consistent with a wider range of pore morphologies, connectivities, and cementation styles at Site 816. For example high Archie $m$ values (greater than 3 ) suggest the presence of poorly connected vugs, while very low values (less than 1.5 ) suggest highly 


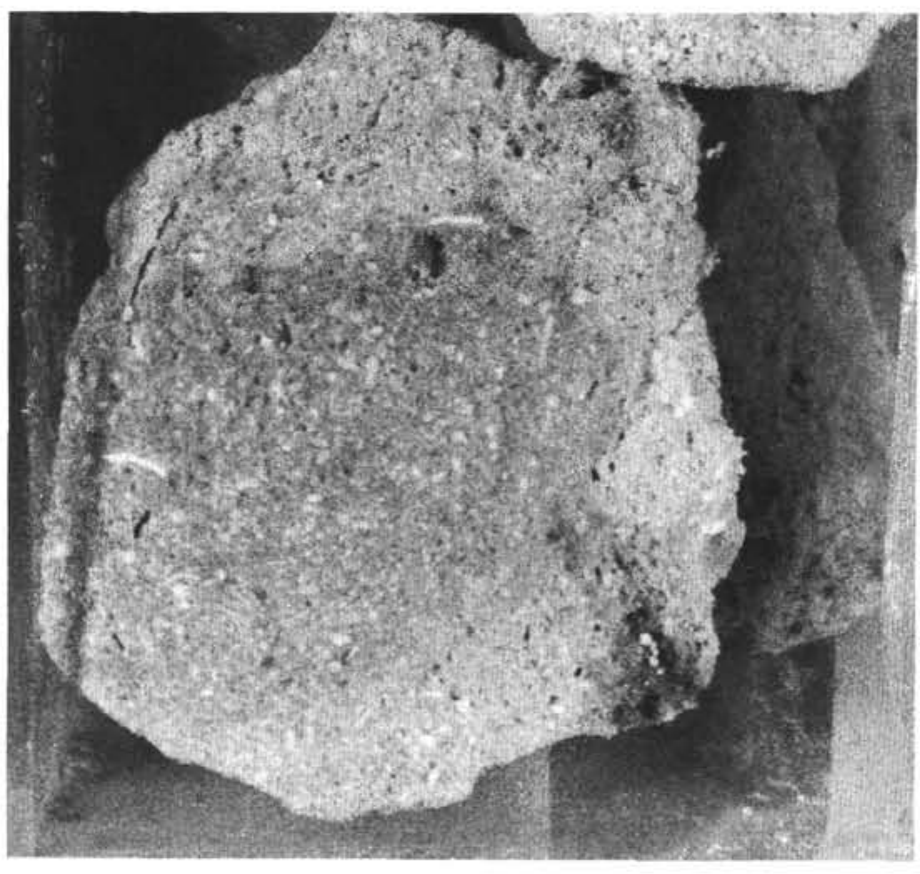

$10 \mathrm{~mm}$

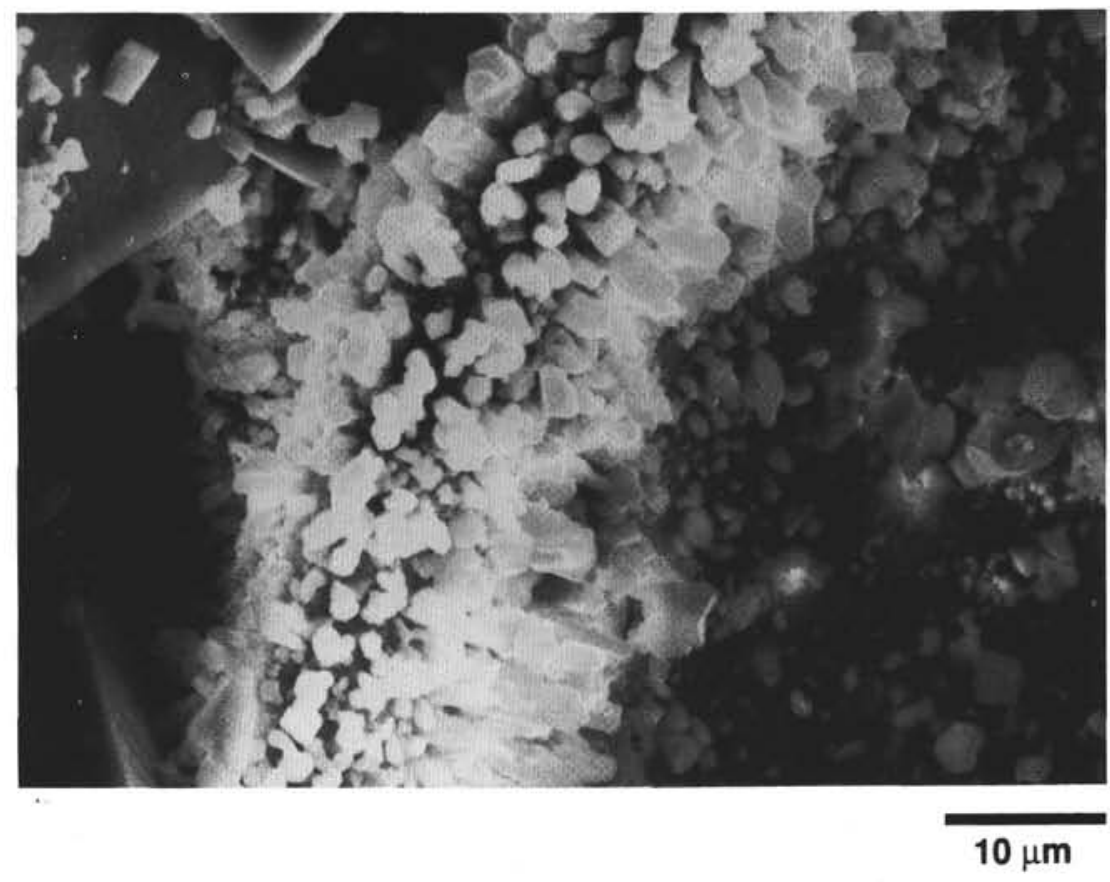

Figure 8. Sample 133-814A-18X-1, 4-10 cm; highly porous, lithified, dolomitized, bioclastic packstone having a moldic porosity style with recrystallized calcite on pore walls that does not appear to block pore throats. 
Formation Factor

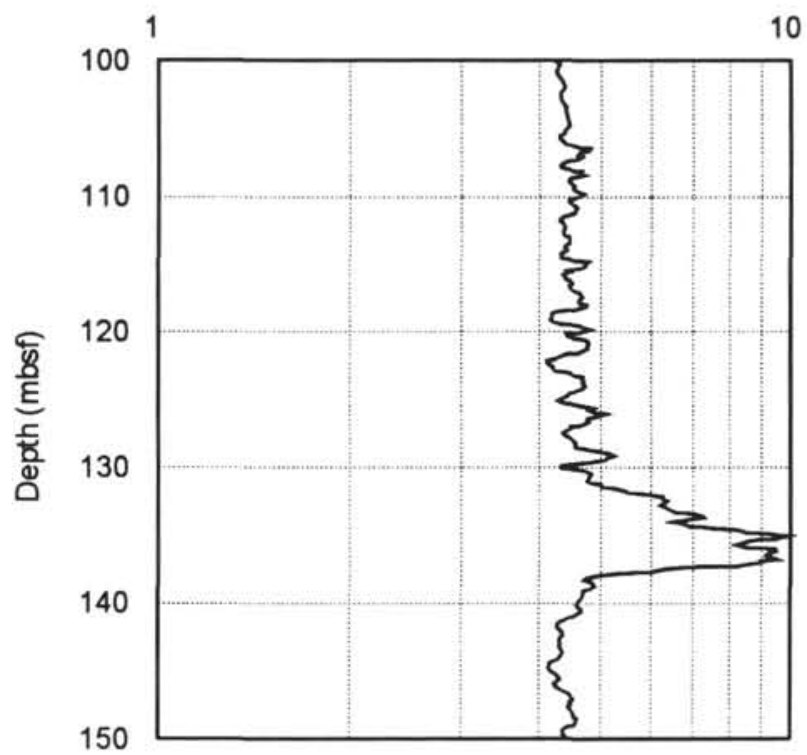

Velocity $(\mathrm{km} / \mathrm{s})$

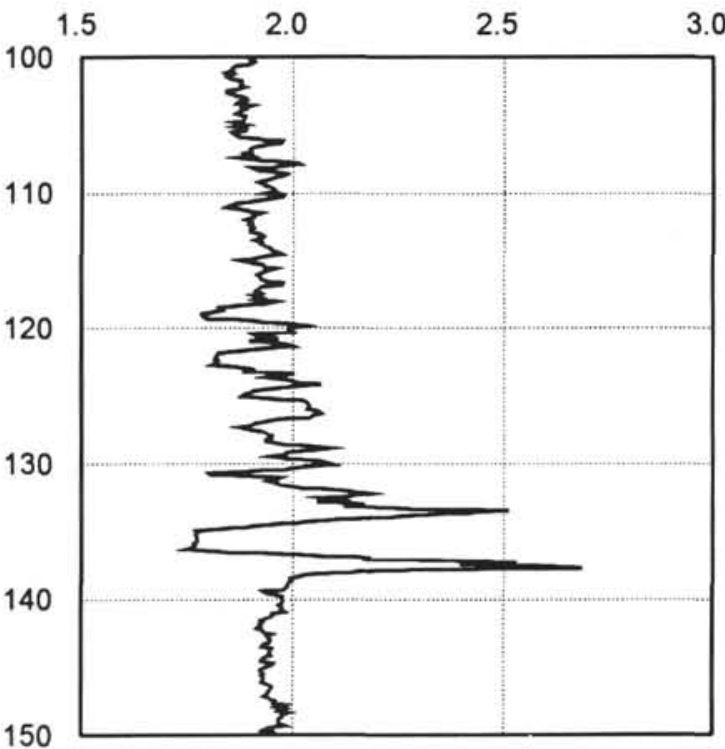

Figure 9. Downhole logs of velocity and resistivity showing a low velocity/high resistivity event at $136 \mathrm{mbsf}$ at Site 824 .

interconnected pore-channels (as previously investigated through numerical modeling) and/or rounded grains having highly interconnected interparticle porosity (Jackson et al., 1978).

The velocity/FF crossplot for Site 816 (Fig. 14) shows two separate relationships; one extends the trend observed at Site 820 (Fig. 13) to higher values of velocity and FF. This relationship is consistent with mechanical compaction at shallow depth and further porosity reduction through greater lithification/cementation in deeper sections. The second trend consists of lower FFs at the same velocities as the primary trend. This second a trend might be indicative of increased porosity within a well-cemented carbonate, where good connectivity results in lower values of FF, while velocity is reduced to a proportionately lesser extent (as described in Fig. 7, Site 814, 150 mbsf). The authors suggest that this effect might be due to an increase in connected porosity caused by a change to re-crystallized euhedral dolomite from "mimic" replacement dolomite (i.e., dolomite that resembles the original calcite) during carbonate diagenesis.

The velocity/FF data for the three lithostratigraphic units identified at Site 816 have been re-plotted in Figure 16 and show that each unit has a near-linear response, with Unit II extending the trend of Unit I (Fig. 16) of increasing velocity and FF with depth. Unit III exhibits a different trend of high velocities at low FFs. The difference in velocity/FF trends between Units II and III suggest a major change in cementation/porosity style that, in turn, is indicative of different diagenetic histories between the two units. Mineral composition analyses at Site 816 (Davies, McKenzie, Palmer-Julson, et al., 1991) show extensive dolomitization of both Units II and III.

The authors find that the samples, going downhole, although completely dolomitized, undergo a major textural change. In the upper part of the hole in Unit II the bioclasts, while dolomitized, are preserved and the matrix is still not recrystallized. Deeper in the section there is increasing fabric destruction such that few of the bioclasts are still recognizable and the matrix is completely recrystallized such that it consists mainly of dolomite rhombs. Therefore, the rock is well on its way to becoming a sucrosic dolomite in which none of the original constituents may be identified and there is a marked increase in intercrystalline porosity. The authors postulate that an increase in the connectivity of the porosity will occur as a result of these processes. Pigram et al. (this volume) studied the cement stratigraphy of Site 816 and concluded that vuggy porosity (i.e., due to dissolution) developed as a consequence of exposure during the Middle and early late Miocene, and that dolomitization mostly occurs after this event.

The authors conclude that although the recovery was insufficient to quantify directly any comparisons of cementation and porosity styles from core analyses with parameters derived from downhole log data (e.g., Archie $m$ ) that an increase in connected porosity is a plausible cause for the velocity/FF trends seen in Unit III which, in turn, is postulated to be a consequence of fabric destruction during dolomitization.

\section{VELOCITY/RESISTIVITY RATIO}

A number of examples have been presented to show the combined use of velocity and FF (resistivity) trends as indicators of different styles of cementation and porosity in carbonate-reef environments where diagenesis is a major factor. Site 814 provided an example of a cemented sediment with well-connected porosity (Fig. 7) in which velocity is relatively high compared to resistivity. Site 824 (Fig. 9) illustrates the existence of diverging resistivity/velocity trends within a 10-m-thick layer characterized by extensive porosity associated with re-crystallization which fills the pore throats and reduces pore connectivity.

Consequently, a velocity/FF parameter was developed as a means of identifying cementation/porosity style changes that could be applied generally to velocity and resistivity logs in carbonate environments. The ability of the velocity/FF crossplots to enhance the separation of the two trends at Site 816 (Fig. 14) suggests that a simple ratio of velocity and FF is a suitable approach. This approach is also attractive in that it requires only velocity and resistivity data.

Velocity vs. FF data from Site 816 are shown in Figure 17, where lines of constant velocity/resistivity (VR) ratio have been plotted with VR defined as follows:

$$
\mathrm{VR}=V^{*} / \log 10(\mathrm{FF}),
$$

where

$$
V^{*}=\left(V_{p}-V_{\text {water }}\right) / V_{\text {water }}
$$

and where $V_{p}$ is the formation compressional-wave velocity, $V_{\text {water }}$ equals pore-fluid velocity, and $\mathrm{FF}=$ formation resistivity/formation fluid resistivity. 

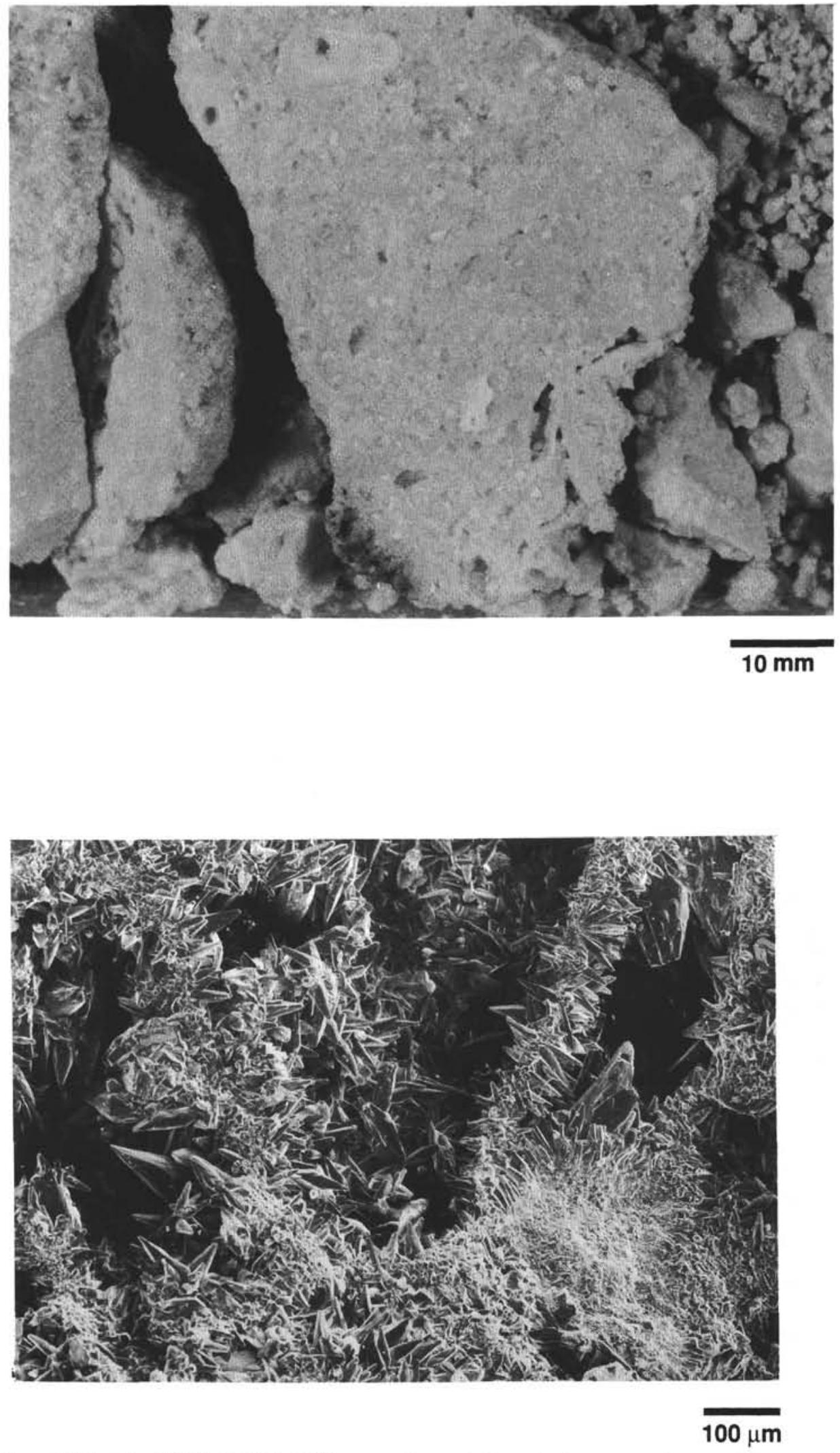

Figure 10. Sample 133-824A-10H-1, 79-80 cm; well-cemented sample showing poorly connected vugs and substantial recrystallization that blocks pore throats. 


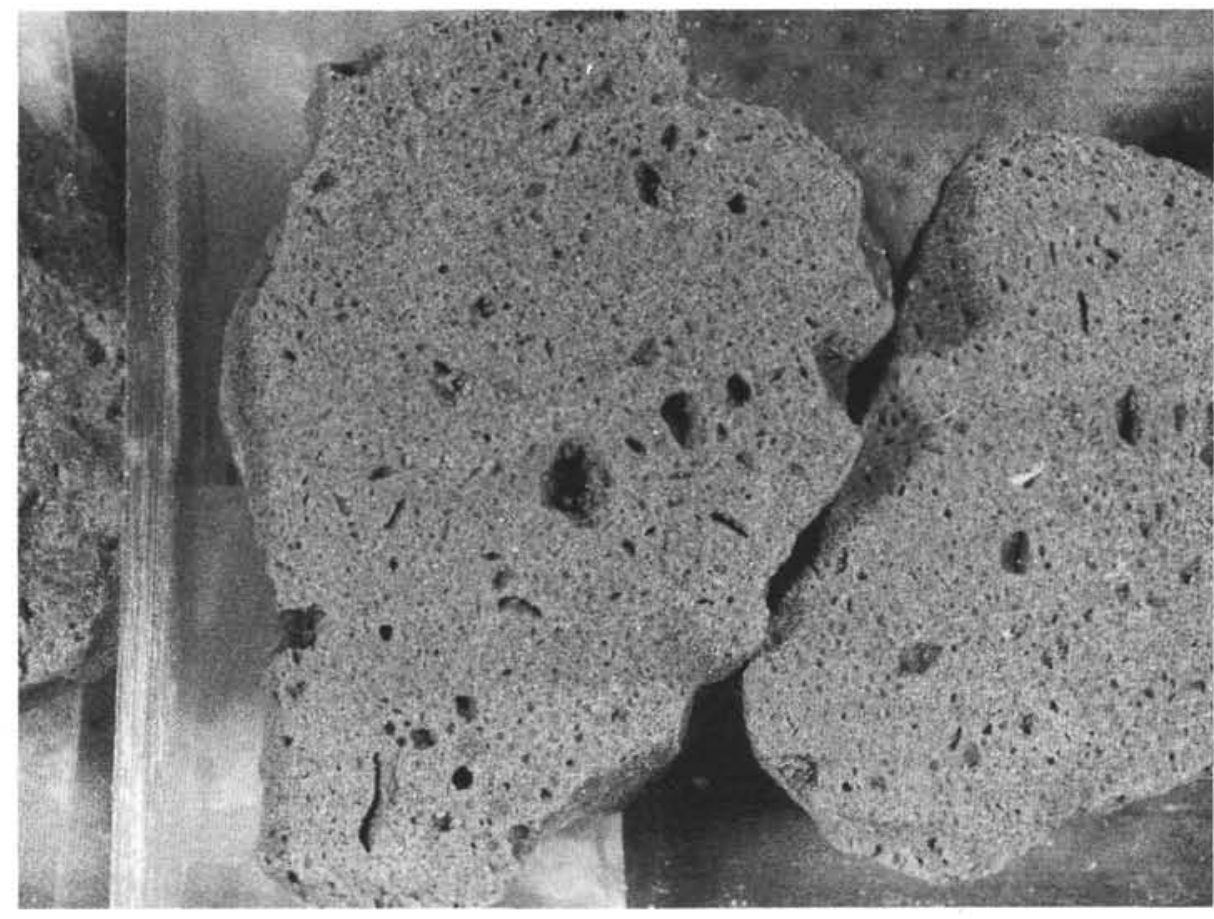

$10 \mathrm{~mm}$

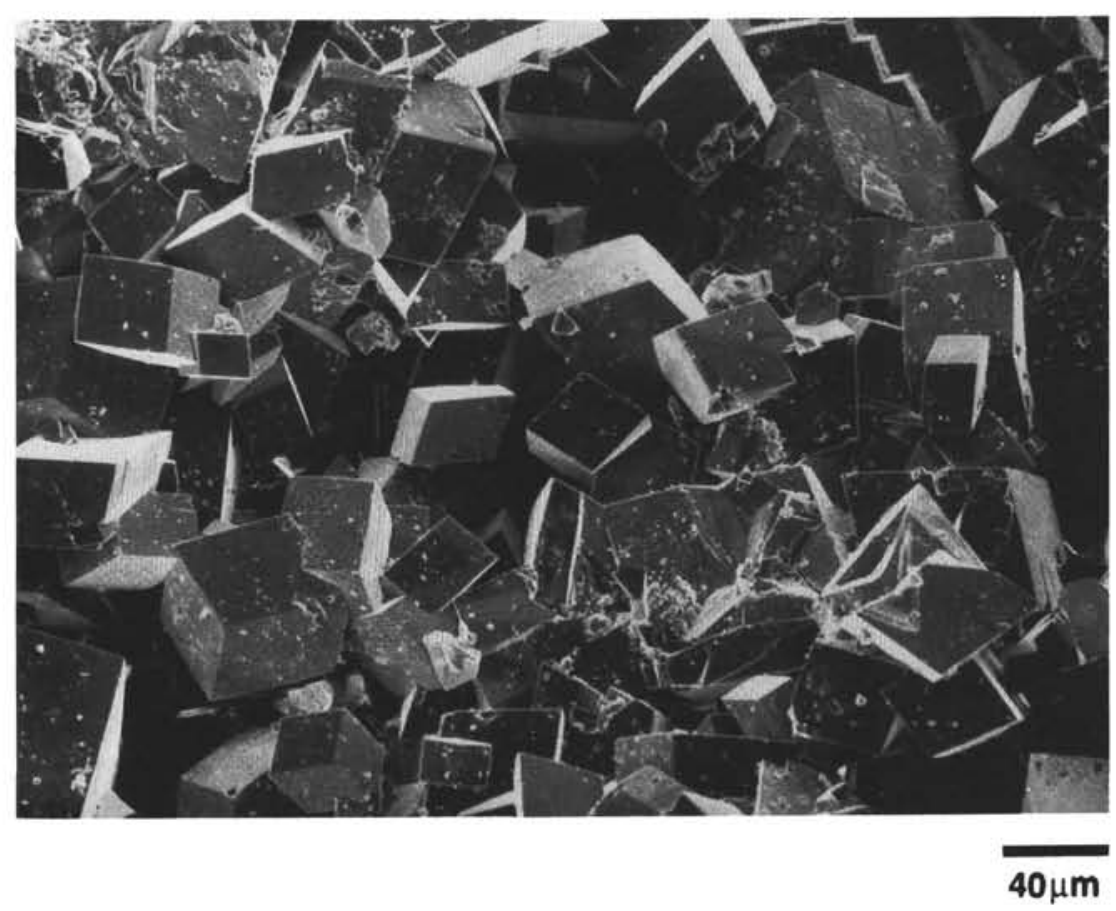

Figure 11. Sample 133-817D-38R-1, 17-20 cm; dark, sucrosic dolomite with vugs and molds. The SEM photomicrographs show euhedral dolomite crystals. 


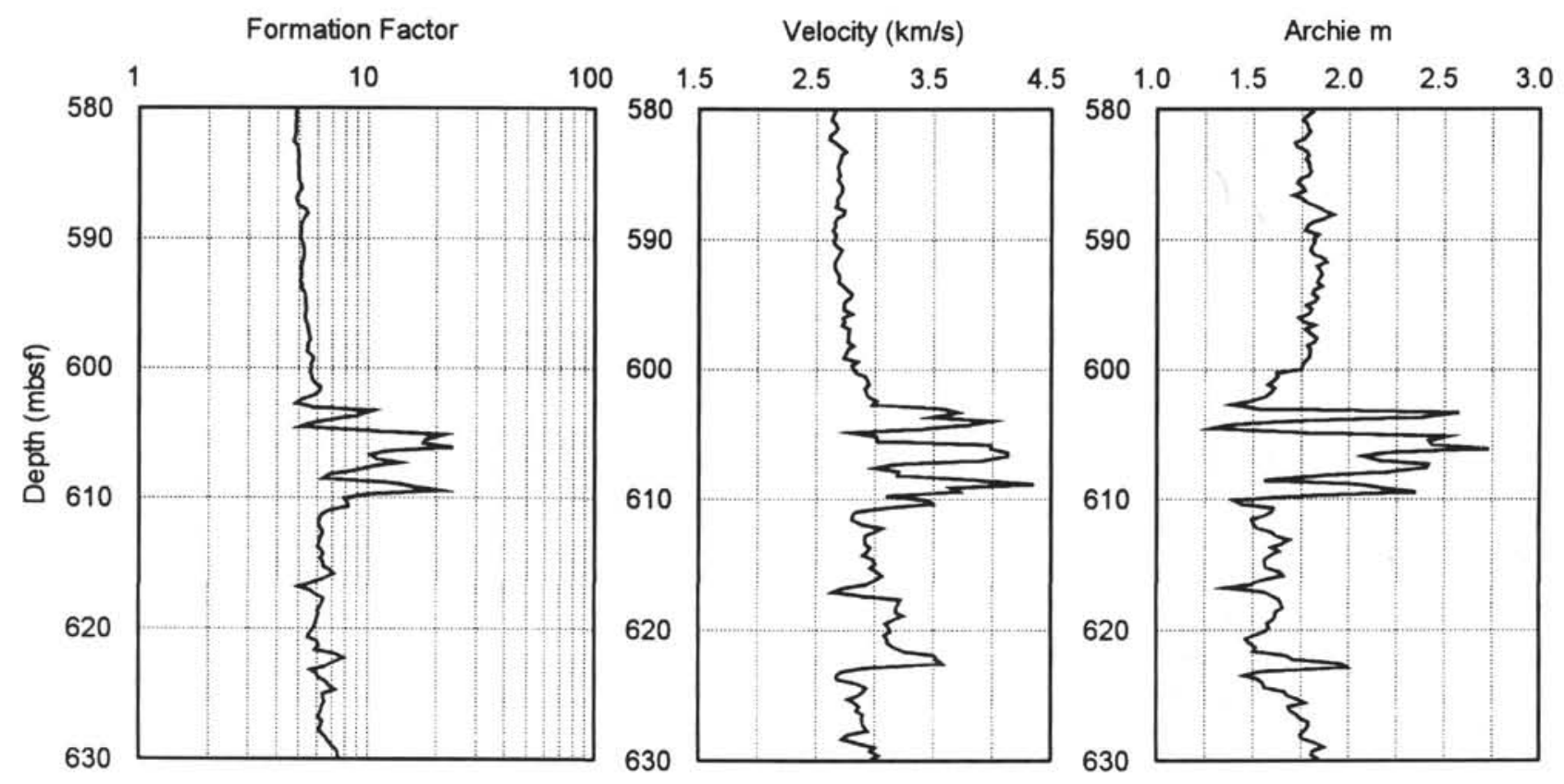

Figure 12. Downhole log data at Site 817 showing higher values of FF, velocity, and Archie $m$ over the interval corresponding with samples in Figure 11 (605-610 mbsf at Hole 817D).
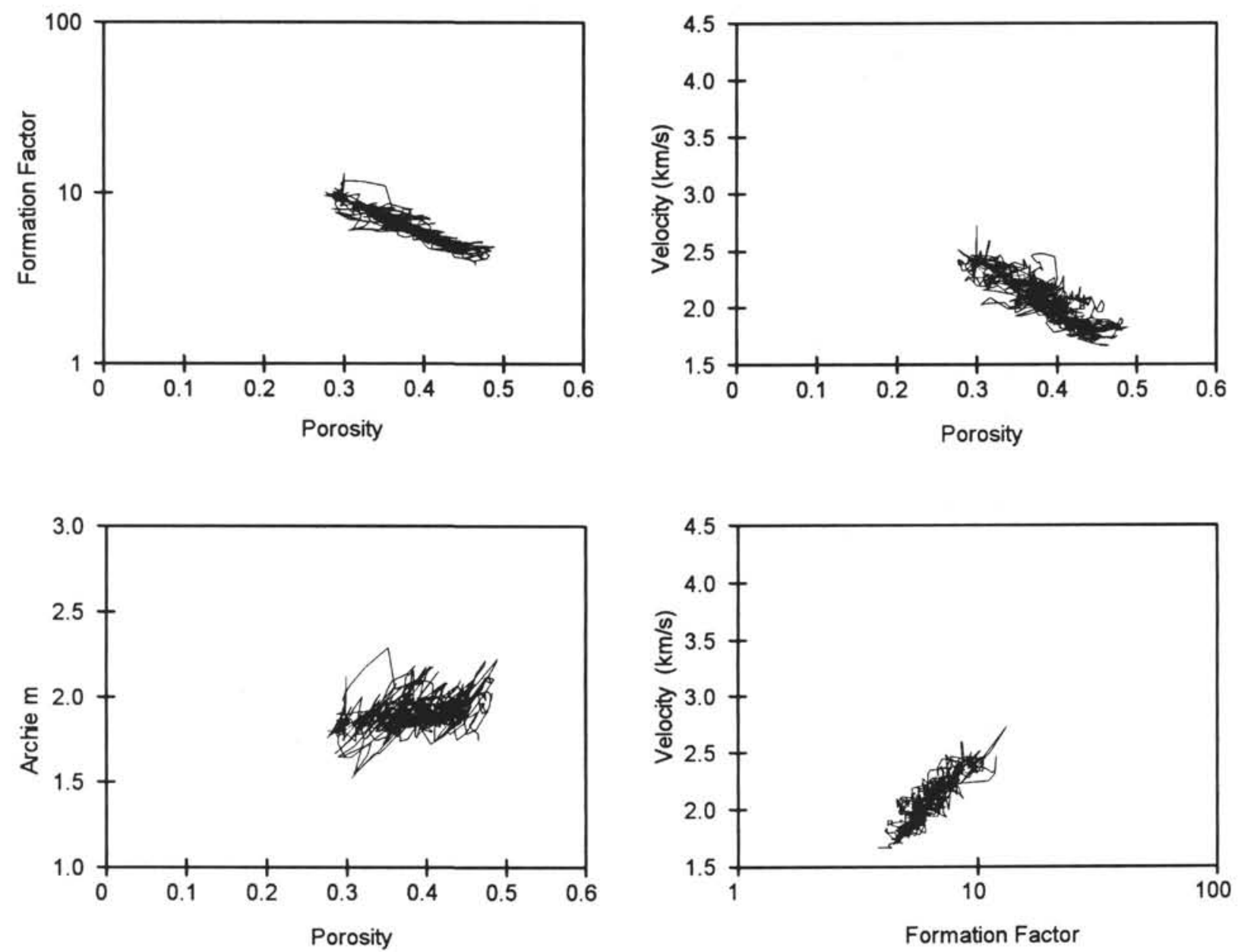

Figure 13. Velocity vs. porosity, FF vs. porosity, Archie $m$ exponent vs. porosity and velocity vs. FF for Site 820 from downhole logs. Lines connecting data values (from points that are adjacent downhole) are plotted. 

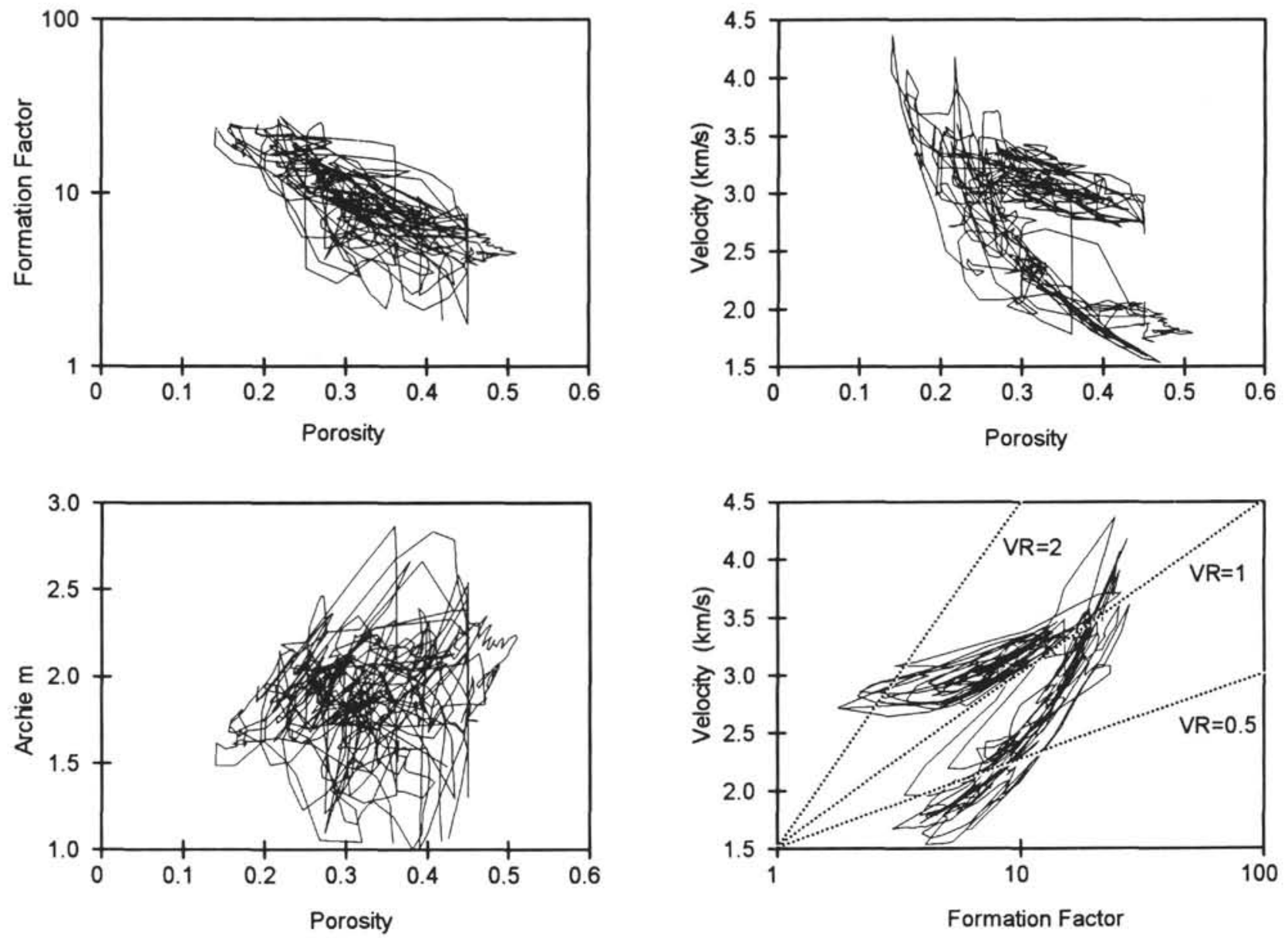

Figure 14. Velocity vs. porosity, FF vs. porosity, Archie $m$ exponent vs. porosity and velocity vs. FF for Site 816 from downhole logs. Lines connecting data values (from points that are adjacent downhole) are plotted.

The ratio VR is dimensionless, being the ratio of two other dimensionless ratios.

The VR ratio uses compressional-wave velocity normalized by the pore-fluid velocity (assumed to be seawater) and $\log _{10}(\mathrm{FF})$, which linearizes the $\mathrm{FF} / n$ relationship with respect to porosity $(n)$ at a constant Archie $m$. The crossplots in Figures 13, 14, 16 and 17 use jointed lines to connect points which gradually increase in depth. This crossplot data is three dimensional in nature, because each point has a depth associated with it. Crossplots displaying data as points do not normally convey depth information. The use of jointed lines to connect individual points provides information about "nearest neighbors" in depth. The crossplots of Site 816 data (Figs. 14 and 16) show that there are wide ranges in properties occurring over very short depth intervals; this is most evident in the velocity/FF plots (Figs. 16 and 17) where the whole range of values is traversed by three or four adjacent points (over 2 to $3 \mathrm{~m}$ downhole) for both Units II and III. The authors conclude that velocity and FF are not related to depth by a general "compaction/lithification" profile (e.g., Urmos et al., in press), but are more likely to be controlled by spatially variable diagenesis.

The theoretical behavior of VR was studied using two models that combine Archie's equation,

$$
\mathrm{FF}=1 / n^{m} \quad(\text { Archie }, 1942),
$$

with either Wyllie et al.'s “time-average" relationship,

$$
n=\left(D t_{\text {rock }}-D t_{m a}\right) /\left(D t_{f}-D t_{m a}\right)(\text { Wyllie et al., 1956) }
$$

or Nobes et al.'s "average" relationship,

$$
D t=(n) D t_{\text {Wood }}+(1-n) D t_{\text {Wyllie }} \quad \text { (Nobes et al., 1991), }
$$

and are designated by the authors as the "Archie and Wyllie" and "Archie and Nobes" models, respectively.

Relationships of FF vs. $n$, velocity vs. $n$, and velocity vs. FF are shown in Figure 18, using the two models with a constant value of the Archie $m$ exponent (2.0). The velocity vs. FF crossplot for the "Archie and Wyllie" model can be seen in Figure 18 to have a value of VR ratio close to 1.0 over a porosity range of 0.1 to 0.6 ; in contrast, the "Archie and Nobes" model has values of VR in the range 0.2 to 1.5 for porosities between 0.1 and 0.6 . The authors conclude that the "Archie and Nobes" model is applicable to the unconsolidated carbonate sediments encountered on Leg 133 (having well-connected interparticle porosity) and that the "Archie and Wyllie" model is applicable to cemented carbonates. Thus, a log of VR vs. depth might start at less than 0.5 in high-porosity unconsolidated sediments and gradually increase to 1.0 as compaction increased, reaching a nearconstant post-cementation value (1.0 to 1.2). These values of VR ratio would be changed if the Archie $m$ exponent changed from a value of 2.0 (i.e a well-connected interparticle porosity style). A decrease in Archie $m$ should increase VR (a decrease in FF relative to velocity), while an increase in Archie $m$ should result in a corresponding decrease in VR. Thus VR might be sensitive to diagenetic changes that create both vuggy (poorly connected and well cemented) and dissolution (e.g., generation of well-connected porosity during dolomitization) porosity styles. 

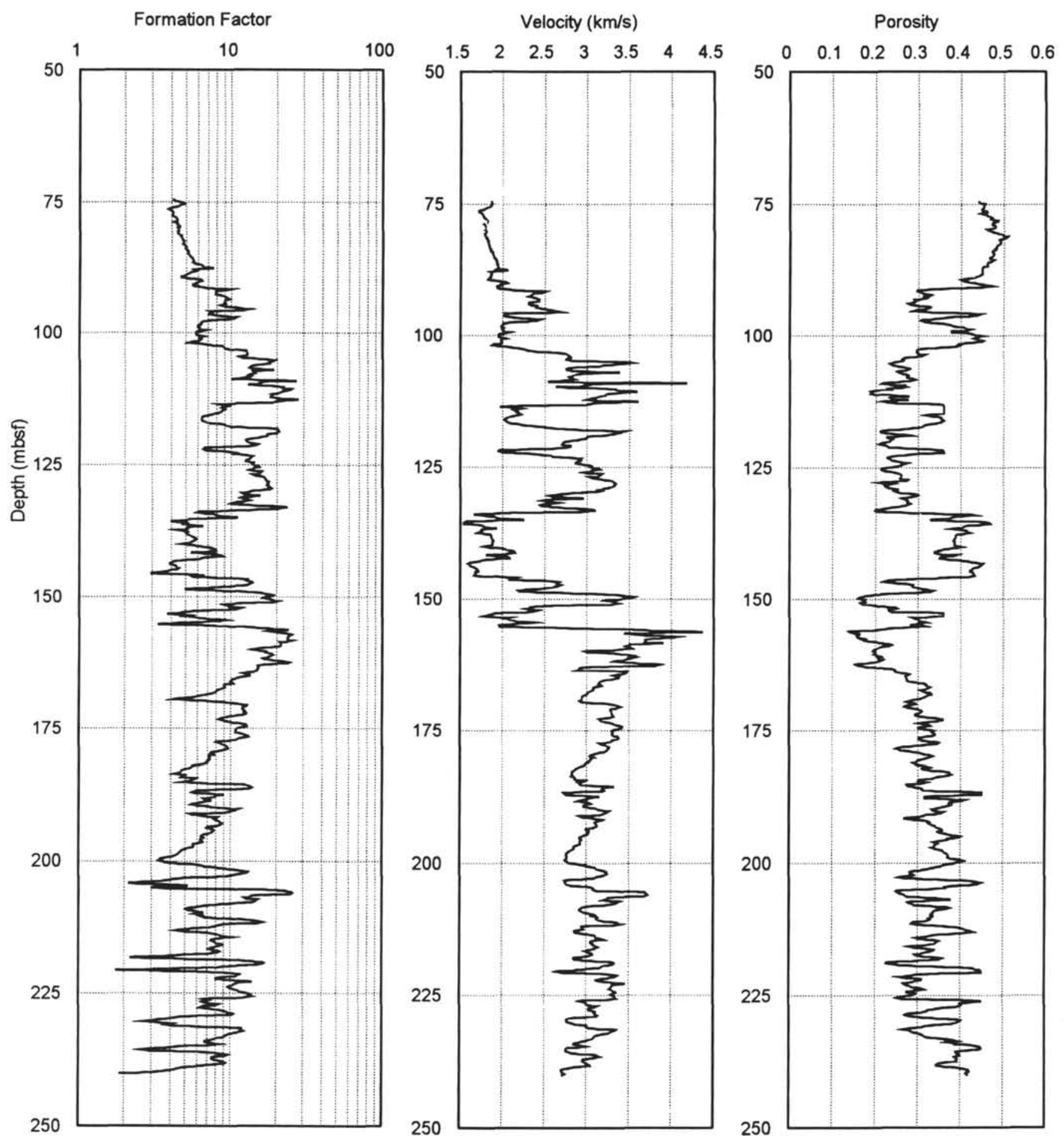

Figure 15. In-situ FF (from resistivity log, corrected for temperature), velocity and porosity (from density) vs. depth at Site 816.

Examples from Leg 133 Sites $814,824,820$, and 817 of VR ratio vs. depth are shown in Figure 19. Data from Sites 814 and 824 show responses to an increase in connectivity at $150 \mathrm{mbsf}$ and an increase in porosity and decrease in connectivity at $136 \mathrm{mbsf}$, respectively (Fig. 19). Thus, one may distinguish the development of unconnected vugs, where pore channels are blocked by recrystallized cement from more connected styles of porosity. Site 820 depicts a compaction profile without substantial diagenesis, while Site 816 (Fig. 20) shows the wide variability that is possible, particularly below $160 \mathrm{mbsf}$ within Unit III (described above).
Using the Site 816 VR log as an example, the gradually increasing VR data for Unit I (above $93.0 \mathrm{mbsf}$ ) are consistent with a high porosity compaction profile, while the large changes in VR for Unit II (93.0 to $163.7 \mathrm{mbsf}$ ) are thought by the authors to indicate, generally, variable cementation within well-connected interparticle porosity. The low values of VR taken alone in the interval 135 to 145 mbsf of Unit II, could be caused by either uncemented unconsolidated sediments or by extensive, poorly connected vuggy porosity. However, the Archie $m$ exponent is generally below 2 in this interval, providing independent evidence that unconsolidated sediments, with 
A Site 816 (Unit I 75-93.0 mbsf)

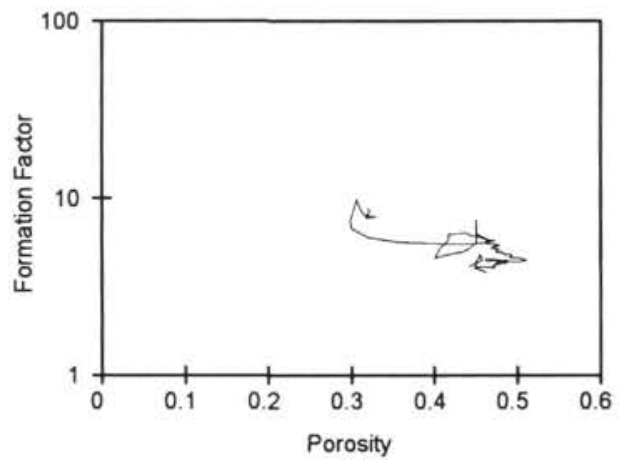

Site 816 (Unit III 163.7-250.0 mbsf)

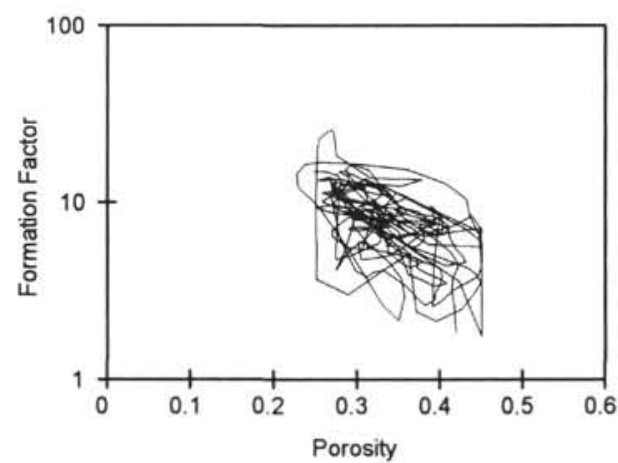

B

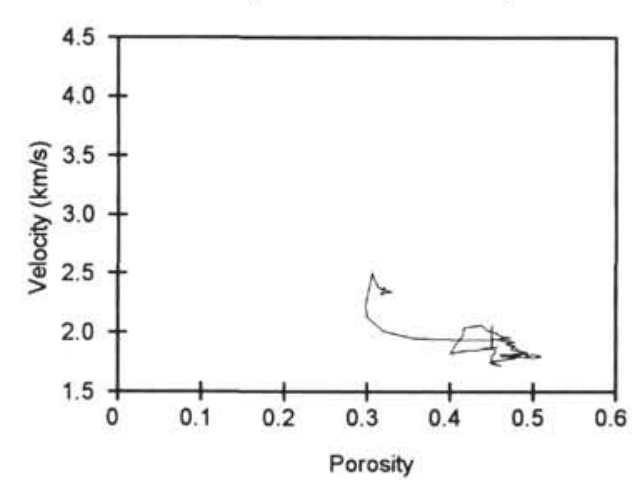

Site 816 (Unit III 163.7-250.0 mbsf)

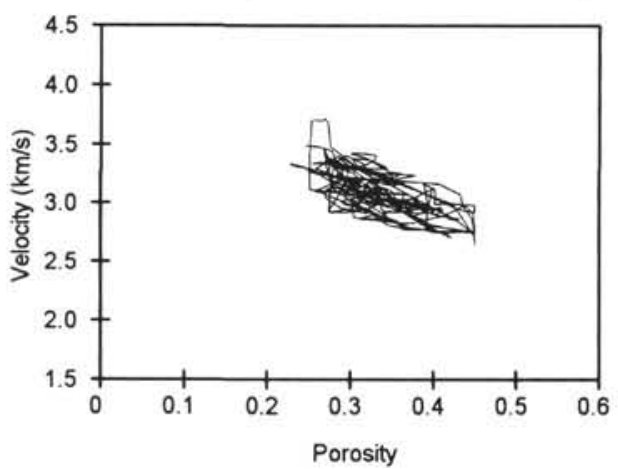

Site 816 (Unit II 93.0-163.7 mbsf)

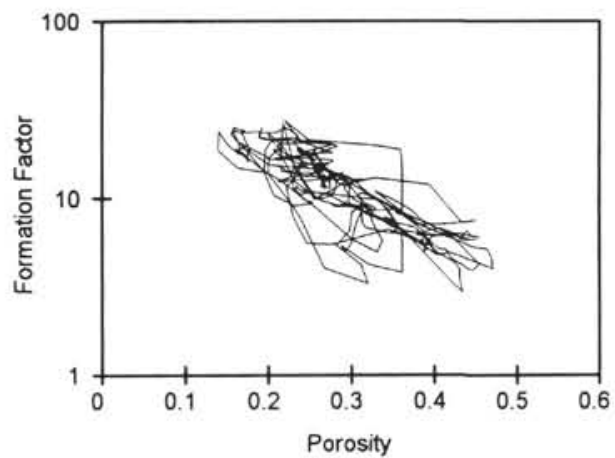

Site 816 (Units I, II \& III)

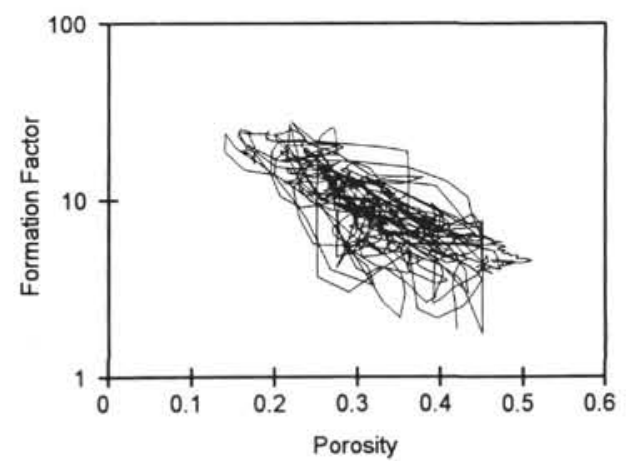

Site 816 (Unit II 93.0-163.7 mbsf)

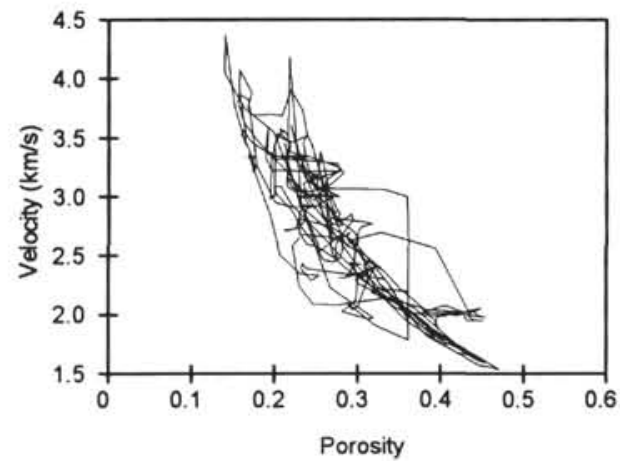

Site 816 (Units I, II \& III)

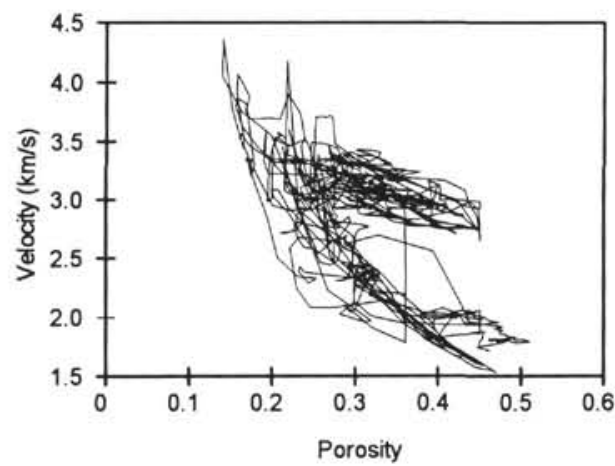

Figure 16. Relationships from the downhole logs at Site 816 for: Unit I, Unit II, Unit III and Units I, II and III combined. A. FF vs. porosity. B. Velocity vs. porosity. C. Velocity vs. FF. Lines connecting data values (from points that are adjacent downhole) are plotted. 
C Site 816 (Unit I 75-93.0 mbsf)

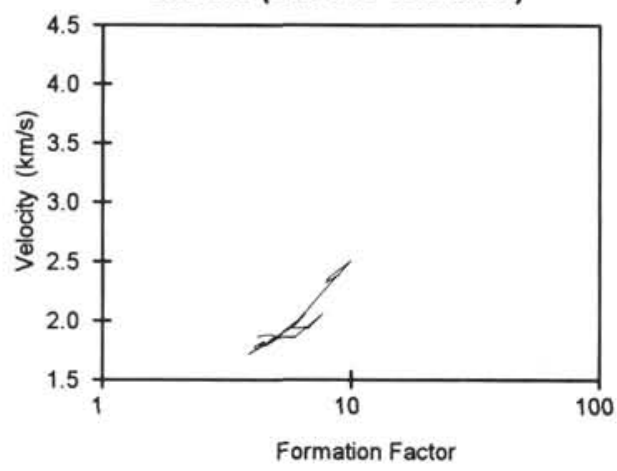

Site 816 (Unit III 163.7-250.0 mbsf)

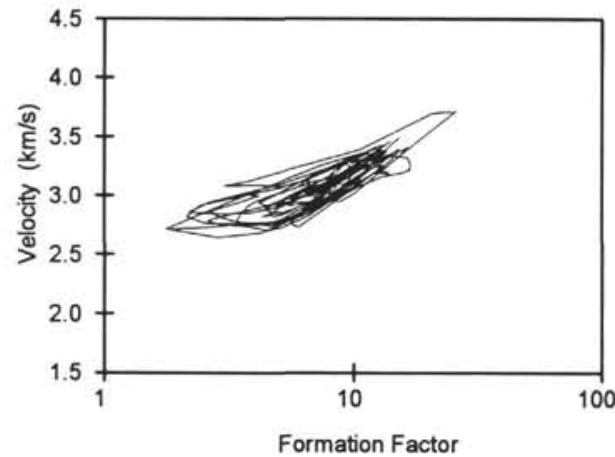

Figure 16 (continued).

well-connected interparticle porosity, are the more likely of the two propositions. By contrast, the VR data for Unit III exhibit a generally constant baseline-value of 1 , with a number of "spike" responses reaching values of over 2.5. The authors propose these responses are due to lithified sediments in which dolomitization has resulted in the creation of a number of thin zones which have extremely well-connected porosity (low Archie $m$ ).

The very high VR spikes in the Site 816 response (Fig. 20) were studied in detail using the downhole FMS. This device produces an orientated electrical resistance image of the borehole wall (Ekstrom et al., 1986). These data are normally processed to enhance correlatable events between the electrode "buttons" at the expense of the absolute values of resistance. The results describe borehole morphology at a measurement density of $0.1 \mathrm{in}$. and are particularly suited for investigating thin layers.

FMS data for the section from 220 to $222 \mathrm{mbsf}$, above and below a layer of very high VR, in Hole $816 \mathrm{C}$ are shown in Figure 21A. The FMS image above and below this layer is consistent with a pore morphology similar to a dolomitized rhodolith-bearing rudstone described on board ship (Section 133-816C-11R-1, $222.3 \mathrm{mbsf}$ ), having substantial connected porosity, as shown in Figure 22 (Davies, McKenzie, Palmer-Julson, et al., 1991). The image in Figure 21Auses a 5-m section of the FMS image for "color equalization." Color equalization is a technique where the whole color scale used is applied to the data concerned. This technique removes absolute values from the display, but permits an optimum display of structural data. The use of a multicolor scale highlights high and low resistances, such that pores and well-cemented zones are easily identified. The abrupt change in resistance at $220.7 \mathrm{mbsf}$ corresponds to a thin layer having a very low resistivity, as seen in all the resistivity logs.

Figure 21B, on the other hand, uses a dynamic "color equalization" scheme: a narrow, moving window over which the whole color range
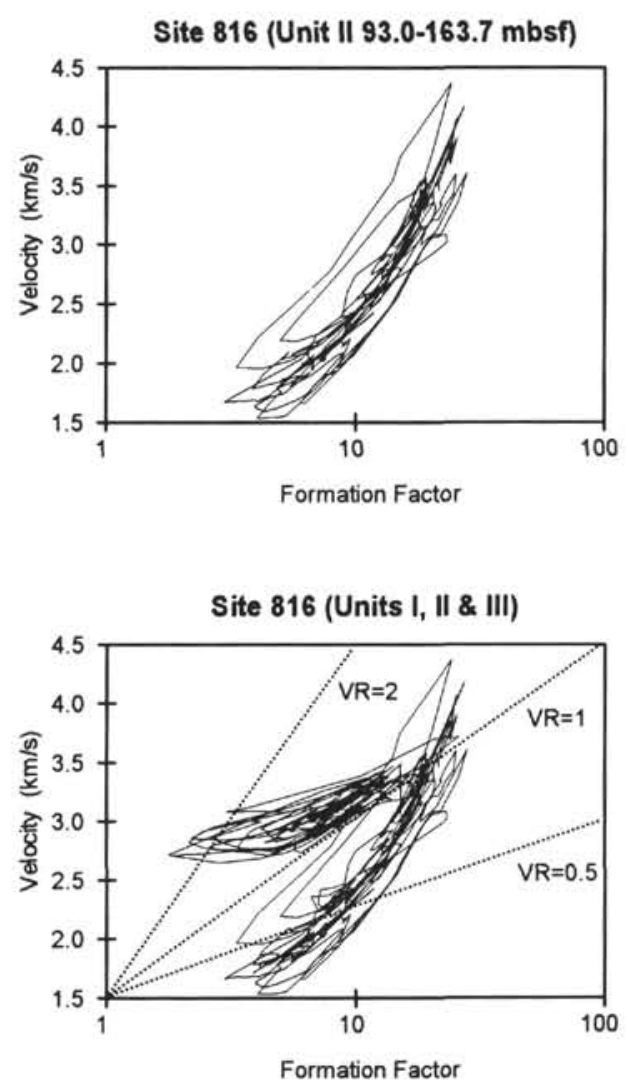

is applied. This arrangement enables one to see greater detail at a particular depth around the circumference of the borehole; however, changes in color at different depths cannot necessarily be correlated.

A comparison of Figures $21 \mathrm{~A}$ and $21 \mathrm{~B}$ suggests that the thin layer at $220.7 \mathrm{mbsf}$, having very low resistivity, has an internal structure that suggests a "conduit" of even higher connectivity than is typical for the interval. The low resistance zone seen in Figure 21B may have been caused by a cavity or very large mold that intersected the borehole; however the resistivity logs have depths of investigation of at least $1 \mathrm{~m}$, suggesting that the zone is a major connection in the formation.

The Archie $m$ values shown in Figure 20 are very low at the depth of the low resistivity zone ( 220.7 mbsf), and are consistent with a single "connection-style" such as a conduit or a fracture, as shown by the results of the three-dimensional numerical modelling of a single uniform pore channel, where all of the fluid transports the electric current uniformly. Caving or hole enlargement is an unlikely cause of this phenomenon, as this probably would result in poor pad contact during density logging (and low density values), which, in turn, should increase both the calculated porosity and Archie $m$.

Thin-section analyses of core samples from this low-resistivity, low Archie $m$ zone have indicated the generation of substantial connected porosity on a microscale. An example is shown in Figure 23, where the porosity consists of both extensive intercrystalline pores within the dolomite matrix and vugs (black holes). Core recovery was poor in the interval from 200 to $246 \mathrm{mbsf}$ at Site 816 , leading to uncertainty about the exact depth at which each sample was taken; however, the recovery in Section 133-816C-11R was 33\% compared with an average of $4 \%$ to $8 \%$ for the lower unit at Site 816 (Davies, McKenzie, Palmer-Julson, et al., 1991). The samples from Unit III of Hole 816C generally show similar porosities to each other, based on thin-section studies. They are completely dolomitized and well cemented, while retaining substantial porosity. The pore types vary, but are predominantly intercrystalline 


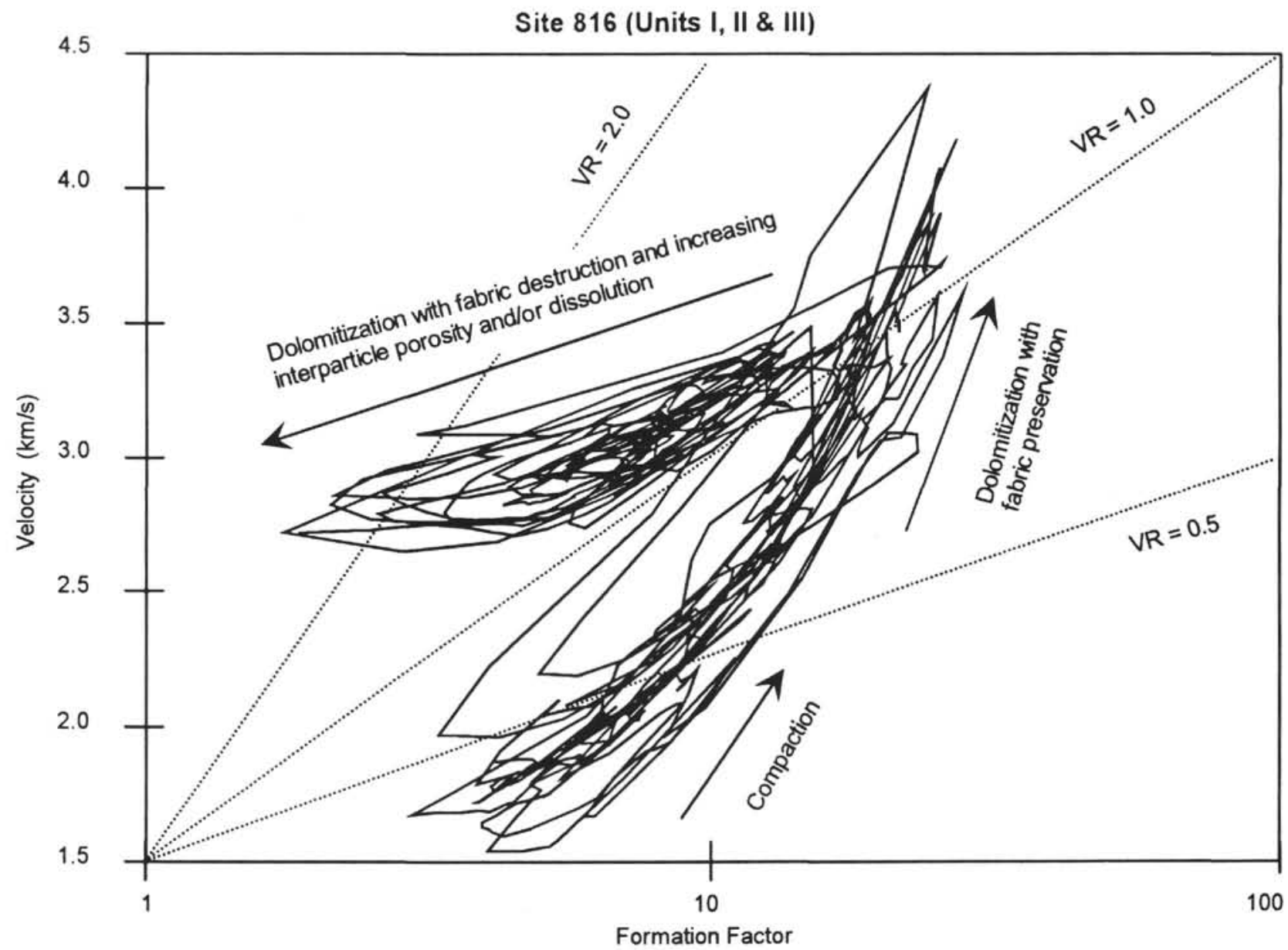

Figure 17. Lines of constant velocity/resistivity ratio (VR) superimposed on plot of velocity vs. resistivity at Site 816 from downhole logs. Lines connecting data values (from points that are adjacent downhole) are plotted.

and generally $0.05 \mathrm{~mm}$ or less in diameter. Intraparticle, vuggy, and minor moldic porosities also are evident. The style of solution porosity (vuggy) is shown in Figure 22; this can be up to several millimeters wide and irregular in shape. Connected porosity seen in thin sections and the ease at which the samples could be re-saturated give qualitative indications of good pore connectivity. Laboratory analyses confirmed these initial observations showing high porosities and permeabilities below a depth of $200 \mathrm{mbsf}$.

Samples probably were obtained from the layers having higher resistivity (Fig. 15) because they are well cemented and completely dolomitized. The textural style of the borehole wall (shown by the FMS images in Fig. 21A) is consistent with that of the samples obtained (e.g., Fig. 22). The layer having very low resistivity and low Archie $m$ at $221.0 \mathrm{mbsf}$ (Figs. 15,20 and 21) appears to have a markedly different style of porosity, and a far higher absolute value of porosity compared to the adjacent rock mass. This is consistent with significant general development of interconnected interparticle porosity. However, the internal resistance structure of the thin layer, centered at $221.0 \mathrm{mbsf}$ (Fig. 21B), requires further interpretation for one to be confident that a large scale structure has been identified. We conclude that this thin layer at $221.0 \mathrm{mbsf}$ has a very low resistivity, relative to the adjacent formation, and a different style of porosity, which includes two features that span the layer. The high values of the VR ratio (velocity/resistivity) and velocity at $221.0 \mathrm{mbsf}$ at Site 816 are consistent with a cemented interval; all the resistivity logs, however, measured low values, which leads us to conclude that a low resistivity zone extends a distance of at least 1 to $2 \mathrm{~m}$ into the formation. We suggest that this layer is cemented and has a high porosity that is well connected. We further theorize that this porosity is the product of dissolution during exposure and fabric destruction during subsequent diagenesis and is considered to be a major fluid pathway.

The increase in connected porosity (intercrystalline), proposed by the authors to explain the data obtained from Unit III at Site 816, (Fig. 17) was studied theoretically using the "Archie and Wyllie" model, proposed above (with a reduction of the Archie $m$ exponent to be compatible with intercrystalline porosity, and dolomite taken to be the matrix for velocity predictions). Relationships of Archie $m$ vs. porosity and velocity vs. FF, for this model (and the "Archie and Nobes" model for limestone), are displayed in Figure 24. The results show that the "increase in connected porosity trend" seen in the downhole velocity vs. FF data at Site 816 can be predicted theoretically.

\section{CONCLUSIONS}

The combined use of resistivity and velocity logs in shallow-water carbonate lithologies can provide information regarding the connectivity of both the pores and the solid matrix not possible by consideration of either alone. A dimensionless velocity/resistivity ratio(VR) is proposed that combines velocity and resistivity logs in a way that enhances its response to changes in the connectivity of the pore space and sediment fabric, rather than changes in porosity. This ratio can be used, as a function of depth, as a derived $\log$, and also can detect diagenetic trends (Figs. 19 and 20), separating compaction/lithification processes/results from those related to connected solution-porosity within a cemented, dolomitized, shallow-water carbonate. The use of cross-plots (Fig. 17) enhances interpretation because the values of 
" Archie \& Wyllie "
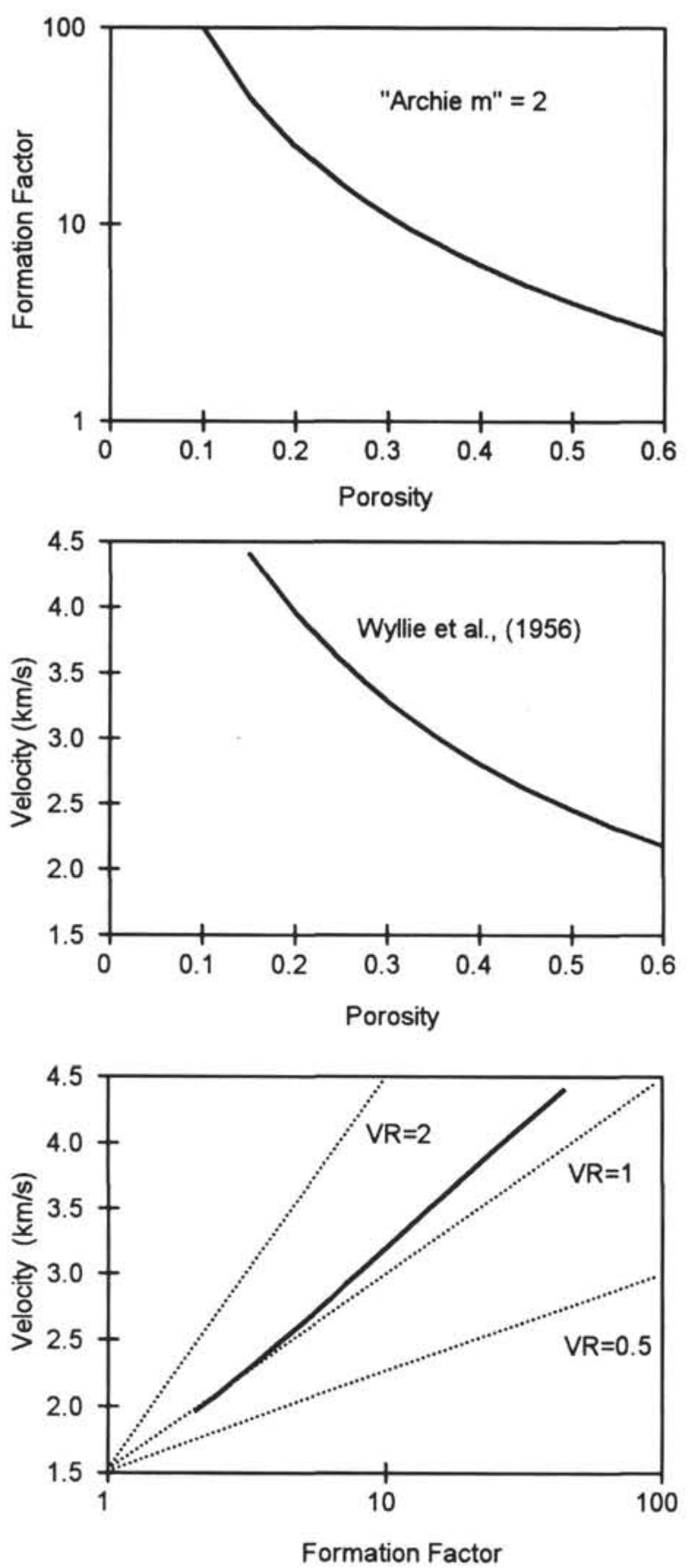

" Archie \& Nobes"
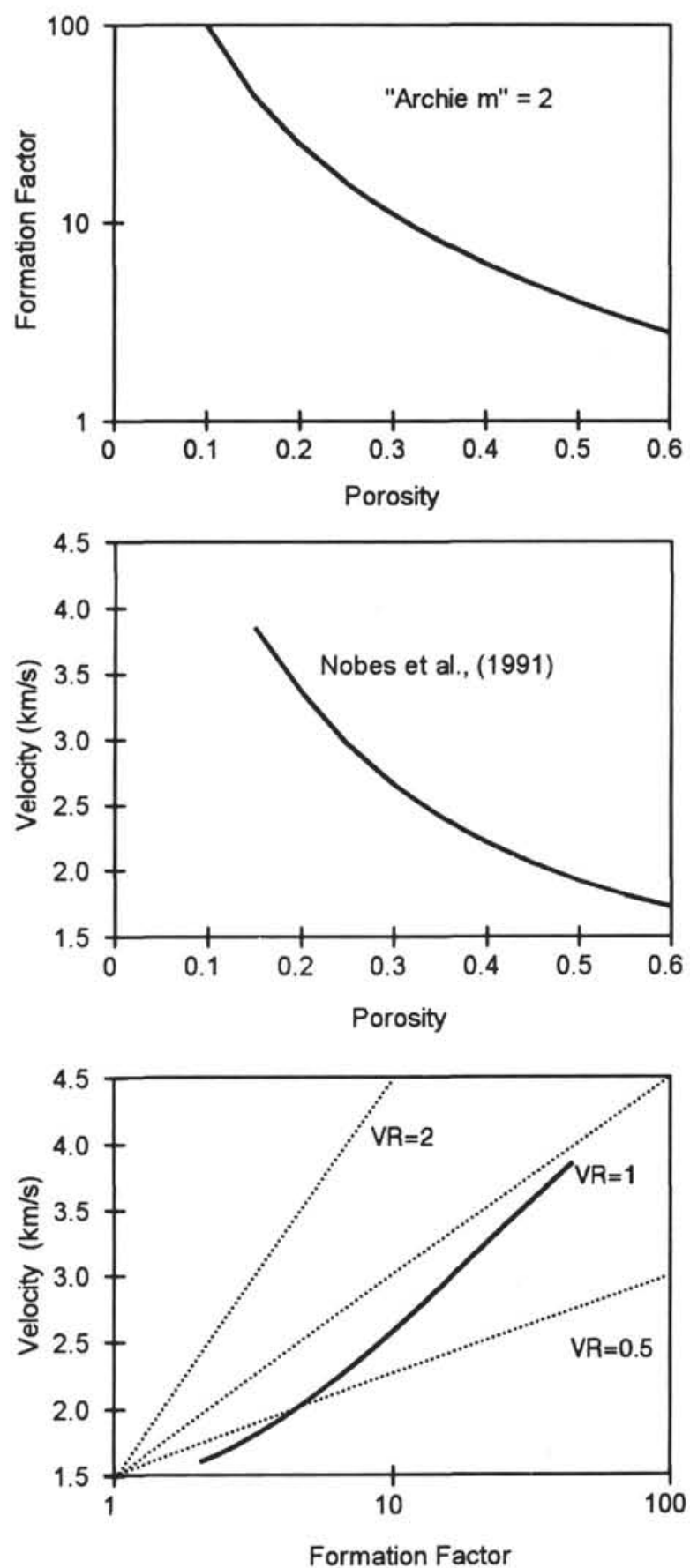

Figure 18. Theoretical models used to predict velocity vs. FF relationships $\left(D t_{m a}=47.5 \mathrm{~ms}\right.$, specific gravity of matrix $=2.71, D t_{f}=201.9 \mathrm{~ms}$, specific gravity (s.g.) of fluid =1.042, for limestone and seawater, respectively, from Hilchie, 1989).

velocity, resistivity, and VR ratio are displayed together, which allows one to distinguish cementation and dissolution from compaction and lithification. For example, throat-blocking recrystallization may be associated with substantial porosity that is poorly connected (e.g., Site 824 , Figs. 9, 10, and 19), which might result in VR values close to those typical of unlithified sediments (e.g., Site 820, Fig. 19, where $\mathrm{VR}=0.5$ ). A combination of theoretical relationships can be used to reconstruct the compaction/lithification and dissolution trends that have been identified by the authors in the downhole velocity vs. FF data (and VR ratio) for Leg 133.
The Archie $m$ exponent is useful for separating moldic and vuggy porosity $(m>2.0)$ from interparticle porosity $(m<2.0$ for carbonate sediments) in sediments that have similar values of VR. When taken together, the VR ratio and Archie $m$ values permit complementary assessments of pore morphology that aid our understanding of diagenetic alterations, particularly the generation of connected porosity and subsequent recrystallization that may block pore throats.

Isolated, high values of VR ratio (spikes seen in the interval from 200 to $246 \mathrm{mbsf}$ at Site 816 ) are indicative of a sequence of thin layers ( $0.6 \mathrm{~m}$ thick) in which substantial connected porosity has developed, 


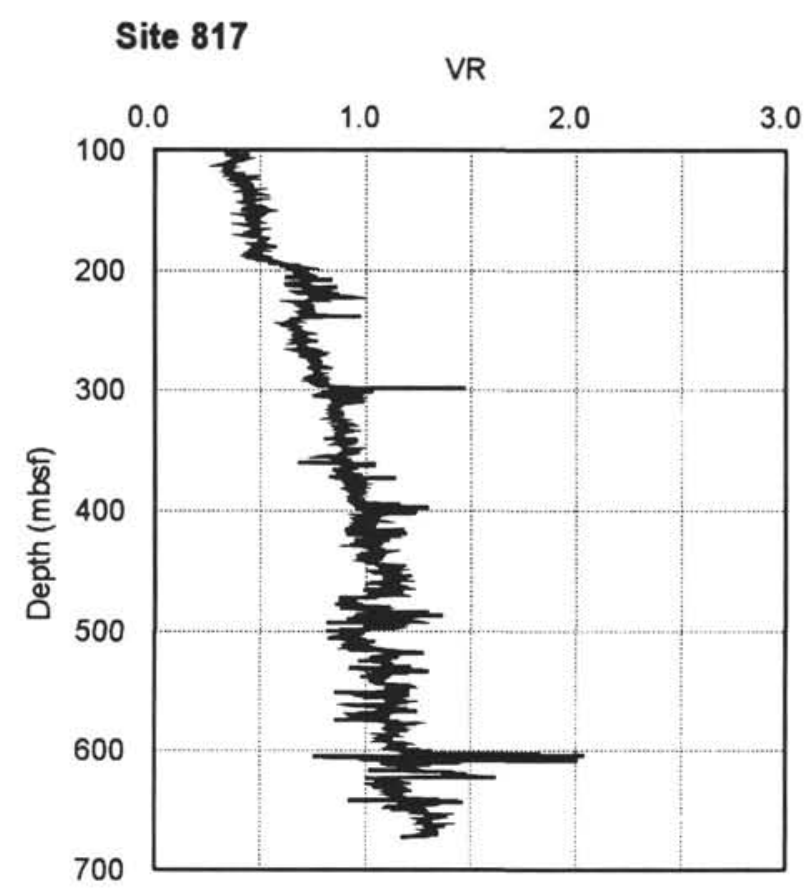

Site 820

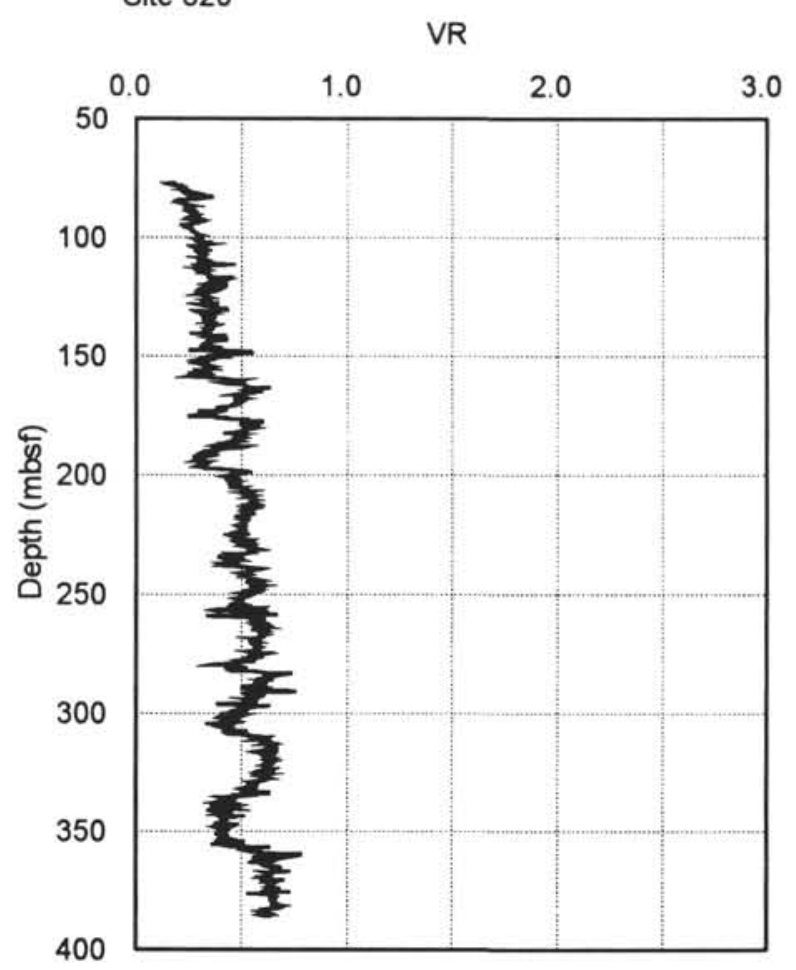

Site 814

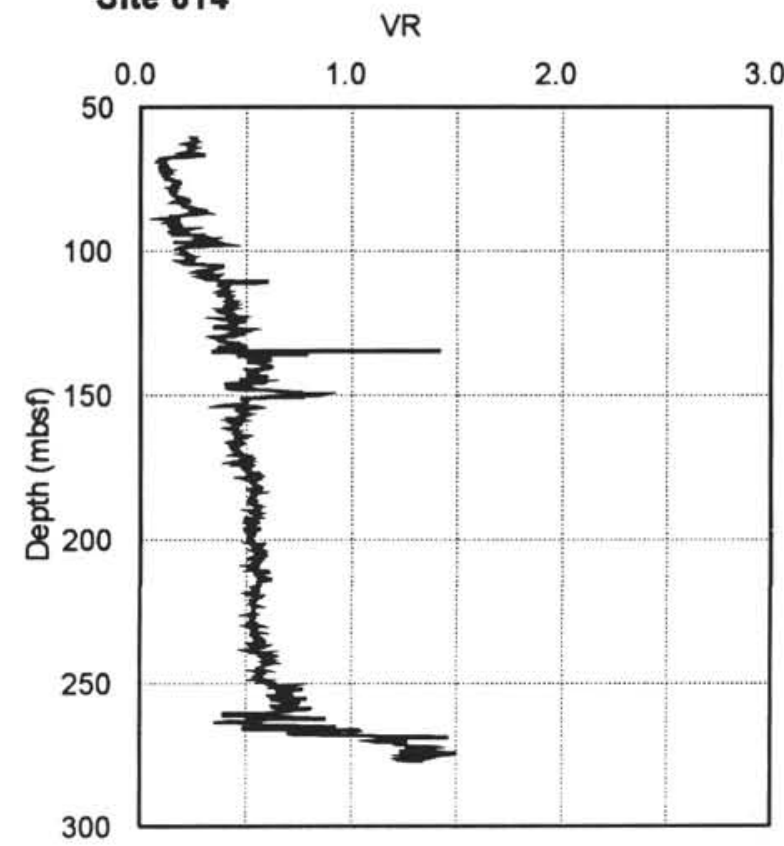

Site 824

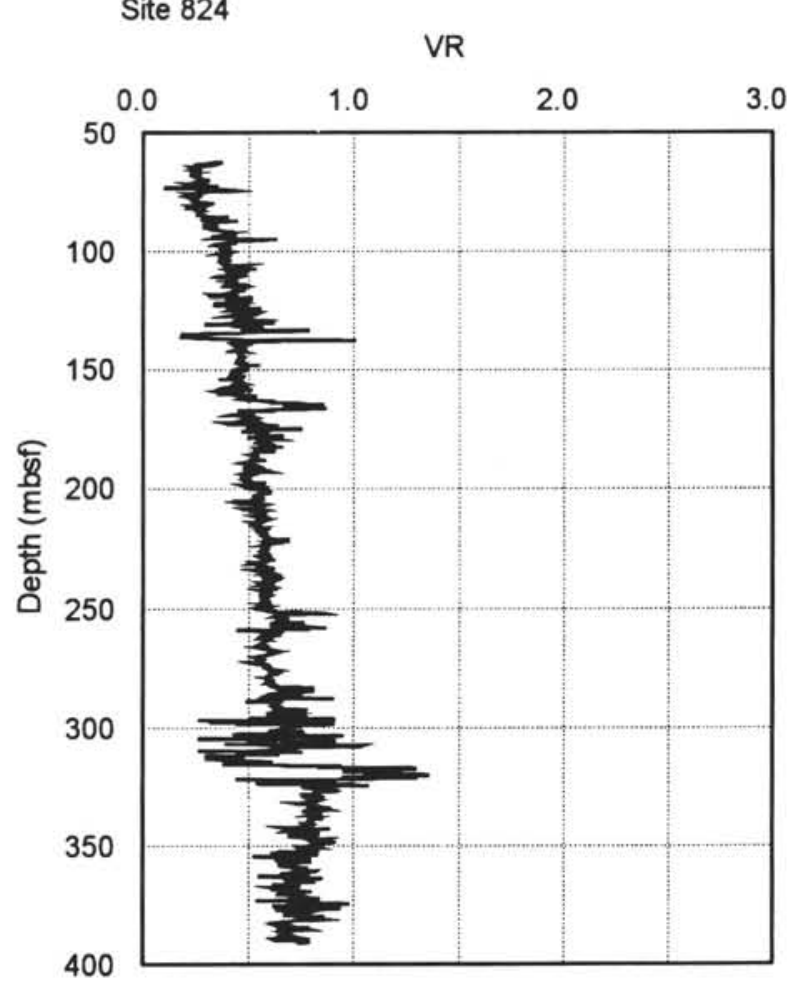

Figure 19. Examples of VR vs. depth at Leg 133 sites illustrating responses to different pore morphologies, and degrees of lithification.

which may result from solution by meteoric waters, as independent evidence for subaerial exposure and freshwater diagenesis can be seen (Davies, McKenzie, Palmer-Julson, et al., 1991). If this is the case, it may be possible to relate these layers having high VR ratios and low values of the Archie $m$ exponent to the position of the paleowater table or the freshwater phreatic zones (Coudray and Montaggioni, 1985).

\section{ACKNOWLEDGMENTS}

This study is published with the permission of the Director, BGS (NERC). CJP publishes with the permission of the Executive Director, Australian Geological Survey Organisation (formerly Bureau Mineral Resources), Australia. This work has been supported by a Natural 
Environment Research Council, ODP Special Topic Grant. The authors wish to thank K.A. Dadey, University of Hawaii, for a thoughtful review that improved the original manuscript.

\section{REFERENCES}

Archie, G.E., 1942. The electrical resistivity $\log$ as an aid in determining some reservoir characteristics. J. Pet. Tech., 5:1-8.

Brace, W.F., Orange, A.S., and Madden, T.R., 1965. The effect of pressure on the electrical resistivity of water-saturated crystalline rocks. J. Geophys. Res., 70:5669-5678.

Coudray, J., and Montaggioni, L., 1985. The diagenetic products of marine carbonates as sea-level indicators. In van de Plassche, O. (Ed.), Sea-level Research: A Manual for the Collection and Evaluation of Data: Amsterdam (Elsevier), 311-360.

Davies, P.J., McKenzie, J.A., Palmer-Julson, A., et al., 1991. Proc. ODP, Init. Repts., 133: College Station, TX (Ocean Drilling Program).

Ekstrom, M.P., Dahan, C.A., Chen, M.-Y., Lloyd, P.M., and Rossi, D.J., 1986. Formation imaging with microelectrical scanning arrays. Trans. SPWLA 27th Ann. Logging Symp., Pap. BB.

Focke, J.W., and Munn, D., 1987. Cementation exponents in Middle Eastern carbonate reservoirs. SPE Form. Eval., 2:155-167.

Fulthorpe, C.S., Schlanger, S.O., and Jarrard, R.D., 1989. In situ acoustic properties of pelagic carbonate sediments on the Ontong Java Plateau. $J$. Geophys. Res., 94:4025-4032.

Gassmann, F., 1951. Elastic waves through a packing of spheres. Geophysics, 16:673-685.

Hilchie, D.W., 1989. Advanced Well Log Interpretation: Boulder, CO (D.W. Hilchie Inc.).

Jackson, P.D., Busby, J.P., Rainsbury, M., Reece, G., and Mooney, P., 1990. The potential of electrical resistivity methods to detect hydraulically connected fractures. In Baria R. (Ed.), Hot Dry Rock [paper presented at Camborne School of Mines Int. Conf.]. Robertson Sci. Publ., 520-532.

Jackson, P.D., Taylor Smith, D., and Stanford, P.N., 1978. Resistivity-porosityparticle shape relationships for marine sands. Geophysics, 43:1250-1268.

Jackson P.D., Williams, G.M., Ward, R., Meldrum, P., and Reece, G., 1991. Electrical resistivity imaging of groundwater problems. Proc. Am. Nuclear Soc., 1991 Winter Meeting, San Francisco.

Jarrard, R.D., Dadey, K.A., and Busch, W.H., 1989. Velocity and density of sediments of Eirik Ridge, Labrador Sea: control by porosity and mineral- ogy. In Srivastava, S.P., Arthur, M.A., Clement, B., et al., Proc. ODP, Sci Results, 105: College Station, TX (Ocean Drilling Program), 811-835.

Laughton, A.S., 1957. Sound propagation in compacted ocean sediments. Geophysics, 22:233-260.

Nobes, D.C., 1989. A test of a simple model of the acoustic velocity in marine sediments. J. Acoust. Soc. Am., 86:290-294.

Nobes, D.C., Mienert, J., and Dirksen, G.J., 1991. Lithologic control of physical-property interrelationships. In Ciesielski, P.F., Kristoffersen, Y., et al., Proc. ODP, Sci. Results, 114: College Station, TX (Ocean Drilling Program), 657-669.

Raymer, L.L., Hunt, E.R., and Gardner, J.S., 1980. An improved sonic transit time-to-porosity transform. Trans. SPWLA 21st Annu. Log. Symp., Pap. P.

Reece, G., 1986. Microcomputer Modeling by Finite Differences: New York (Wiley).

Schopper, J.R., 1967. A theoretical investigation of the formation factor/permeability/porosity relationship using a network model. Geophys. Prospect., 14:301-341.

Urmos, J., Wilkens, R.H., Bassinot, F., Lyle, M., Marsters, J., and Mayer, L., in press. Laboratory and well-log velocity and density measurements from the Ontong Java Plateau: new in-situ corrections to laboratory data for pelagic carbonates. In Berger, W.H., Kroenke, L.W., Mayer, L.A., et al., Proc. ODP, Sci. Results, 130: College Station, TX (Ocean Drilling Program).

Winsauer, W.O., Shearing, H.M., Jr., Masson, P.H., and Williams, M., 1952. Resistivity of brine saturated sands in relation to pore geometry. $A A P G$ Bull., 36:253-277.

Wood, A.B., 1941. A Textbook of Sound: London (G.L. Bell).

Wyllie, M.R.J., Gregory, A.R., and Gardner, L.W., 1956. Elastic wave velocities in heterogeneous and porous media. Geophysics, 21:41-70.

Wyllie, M.R.J., and Southwick, P.F., 1954. An experimental investigation of the S.P. and resistivity phenomena in dirty sands. Trans. AIME, 201:43-56.

- Abbreviations for names of organizations and publication titles in ODP reference lists follow the style given in Chemical Abstracts Service Source Index (published by American Chemical Society).

Date of initial receipt: 13 March 1992

Date of acceptance: 23 March 1993

Ms 133SR-271 

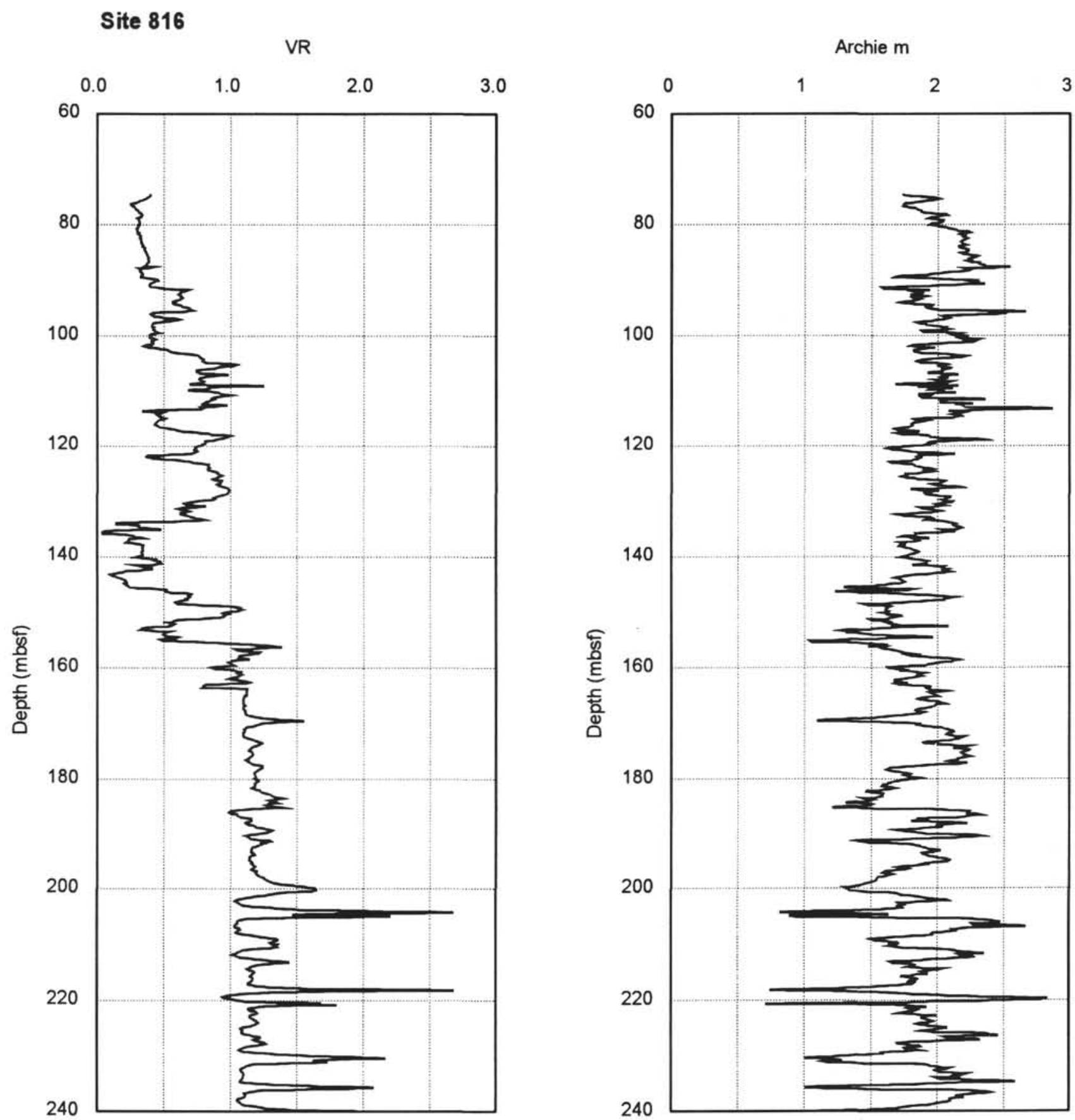

Figure 20. VR and Archie $m$ exponent vs. depth at Site 816 from downhole log data. 


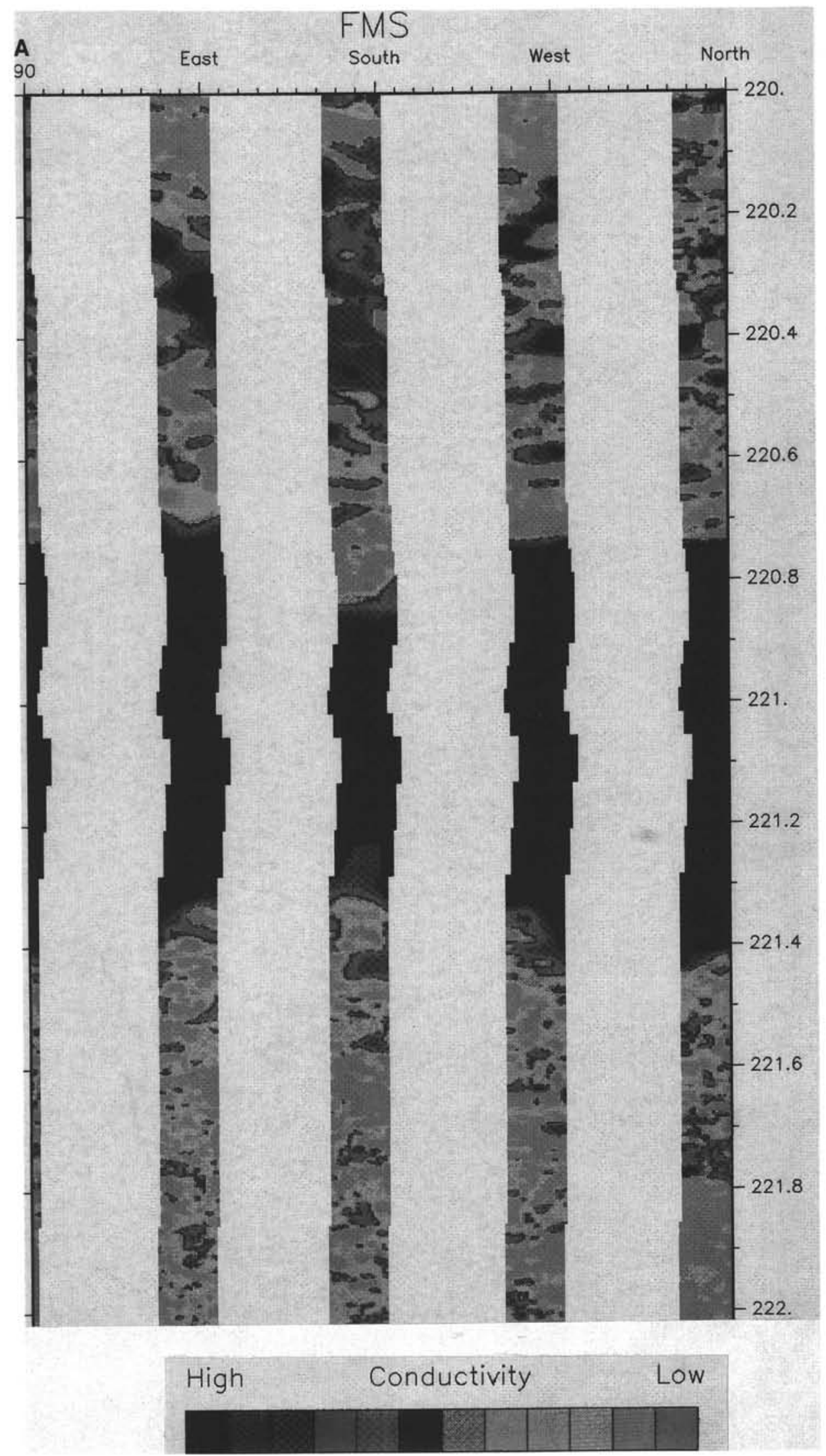

Figure 21. FMS (Schlumberger) images at $220 \mathrm{mbsf}$ at Site 816. A. 5-m static color equalization for extended depth comparisons. B. 0.2-m dynamic color equalization to investigate the structure of thin layers. 


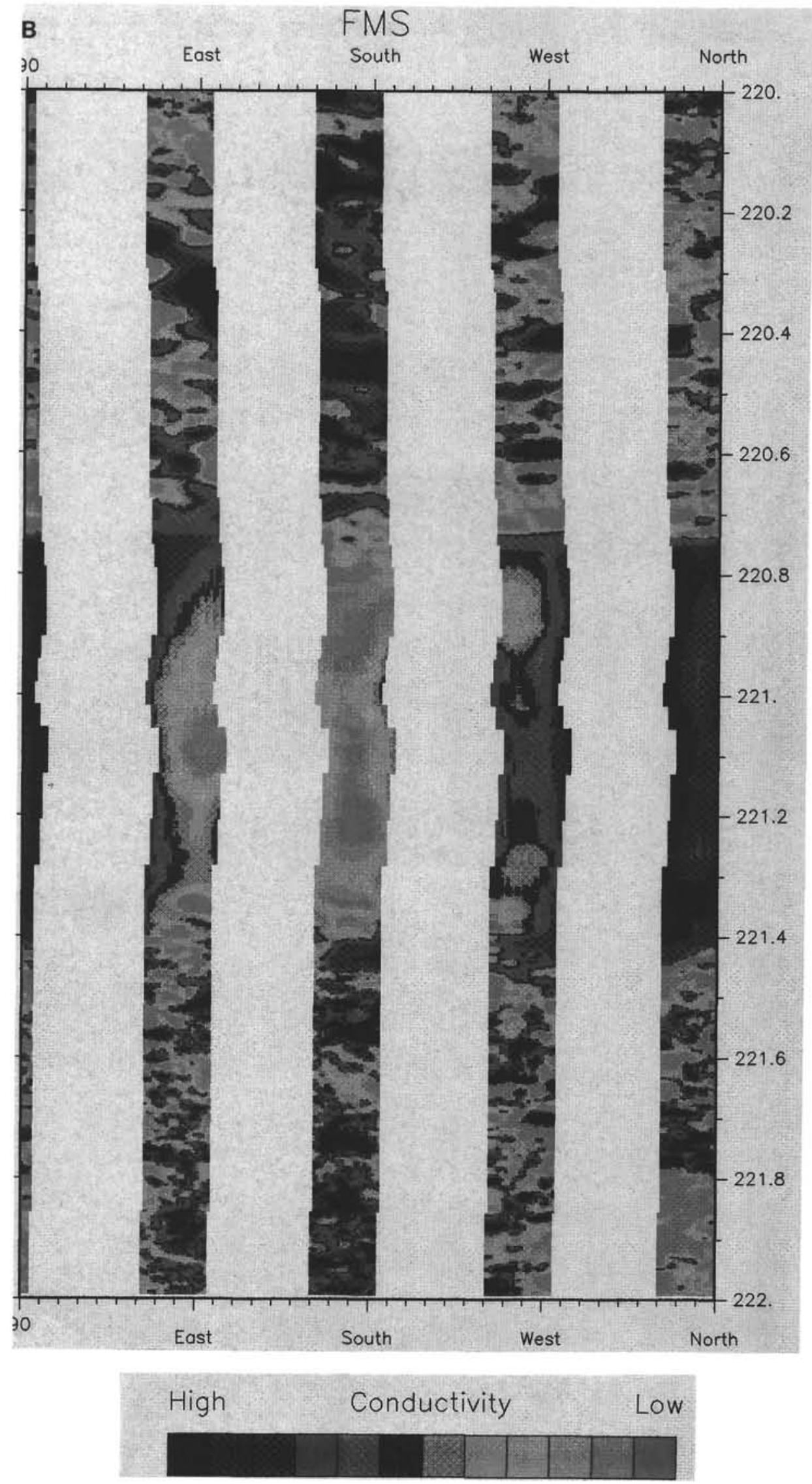

Figure 21 (continued). 


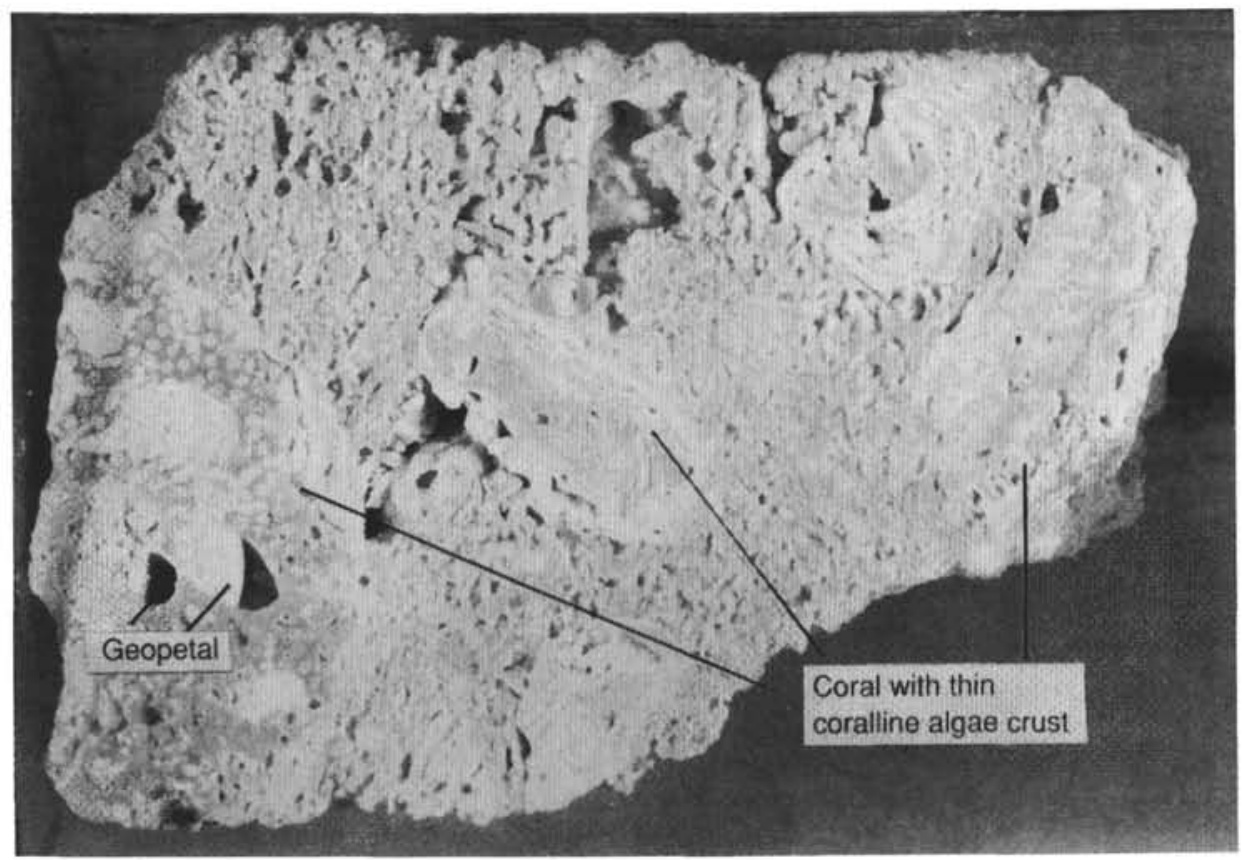

\section{$10 \mathrm{~mm}$}

Figure 22. Example of development of substantial porosity in a dolomitized framestone from Section 133-816C11R-1, 123-138 cm at 222.3 mbsf (after Davies, McKenzie, Palmer-Julson, et al., 1991).

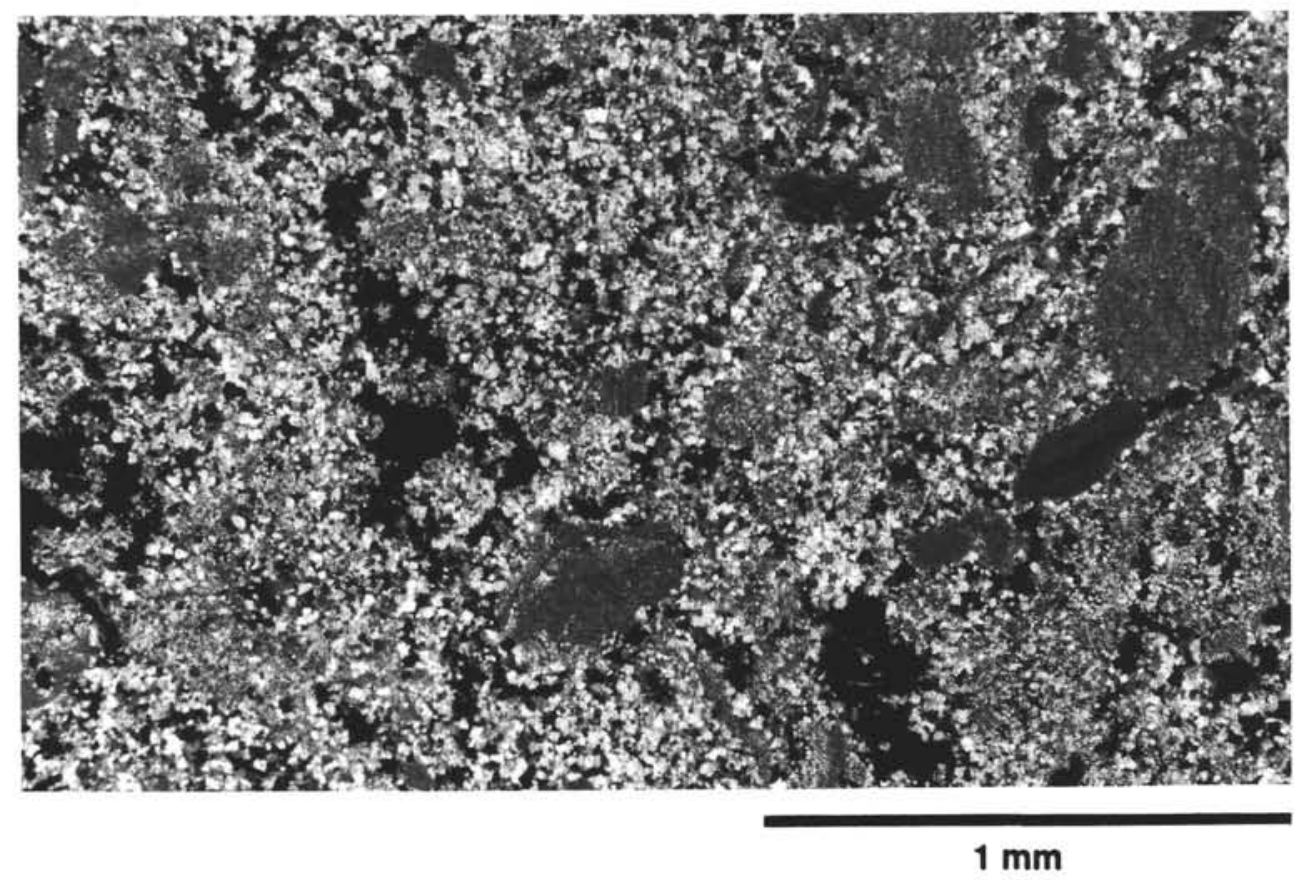

Figure 23. Cross-polarized light thin section from Core 133-816C-11R, at $38-43 \mathrm{~cm}$. Well-developed porosity (irregular black) between dolomite crystals (core from 221 to $230 \mathrm{mbsf}$ ). 

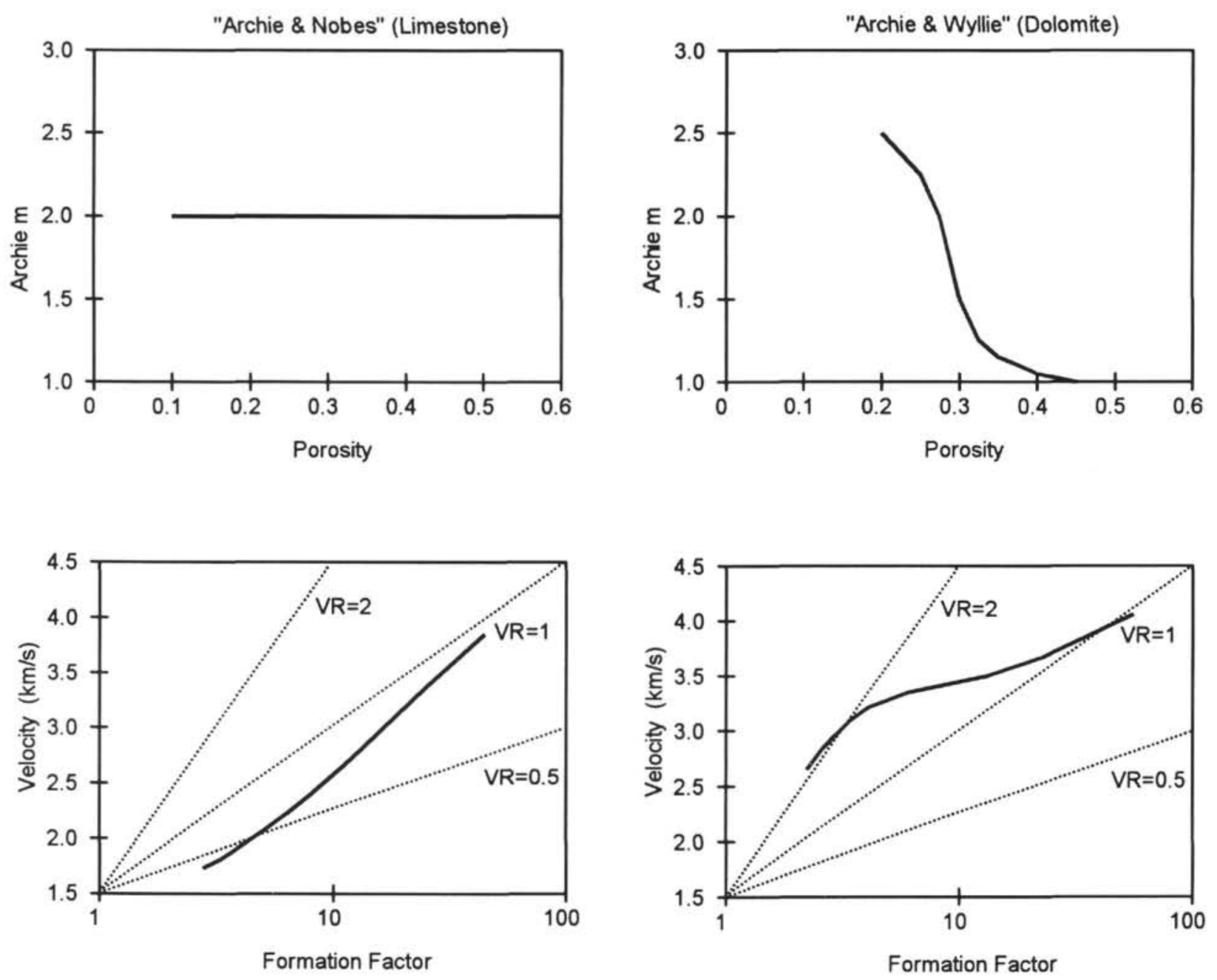

Figure 24. Theoretical models used to predict velocity vs. FF relationships $\left(D t_{\text {limestone }}=47.5 \mathrm{~ms}\right.$, s.g. of limestone $=2.71, D t_{\text {dolomite }}=43.5 \mathrm{~ms}, \mathrm{~s} . \mathrm{g}$. of dolomite $=2.87, D t_{f}=201.9 \mathrm{~ms}$, s.g. of fluid $=1.042$, from Hilchie, 1989). The "Archie and Wyllie" model, with values of the Archie $m$ exponent in the range 1.0 to 2.0 , predicts the velocity vs. FF behavior seen in downhole data from Unit III at Site 816. 